\title{
Solanum torvum responses to the root-knot nematode Meloidogyne incognita
}

Paolo Bagnaresi ${ }^{1}$, Tea Sala ${ }^{2}$, Tiziana Irdani ${ }^{3}$, Cristina Scotto ${ }^{3}$, Antonella Lamontanara ${ }^{1}$, Massimiliano Beretta ${ }^{4}$, Giuseppe Leonardo Rotino ${ }^{2}$, Sara Sestili ${ }^{5}$, Luigi Cattivelli ${ }^{1}$ and Emidio Sabatini $i^{{ }^{*}}$

\begin{abstract}
Background: Solanum torvum Sw is worldwide employed as rootstock for eggplant cultivation because of its vigour and resistance/tolerance to the most serious soil-borne diseases as bacterial, fungal wilts and root-knot nematodes. The little information on Solanum torvum (hereafter Torvum) resistance mechanisms, is mostly attributable to the lack of genomic tools (e.g. dedicated microarray) as well as to the paucity of database information limiting high-throughput expression studies in Torvum.
\end{abstract}

Results: As a first step towards transcriptome profiling of Torvum inoculated with the nematode $M$. incognita, we built a Torvum 3' transcript catalogue. One-quarter of a 454 full run resulted in 205,591 quality-filtered reads. De novo assembly yielded 24,922 contigs and 11,875 singletons. Similarity searches of the S. torvum transcript tags catalogue produced 12,344 annotations. A 30,0000 features custom combimatrix chip was then designed and microarray hybridizations were conducted for both control and 14 dpi (day post inoculation) with Meloidogyne incognita-infected roots samples resulting in 390 differentially expressed genes (DEG). We also tested the chip with samples from the phylogenetically-related nematode-susceptible eggplant species Solanum melongena. An in-silico validation strategy was developed based on assessment of sequence similarity among Torvum probes and eggplant expressed sequences available in public repositories. GO term enrichment analyses with the 390 Torvum DEG revealed enhancement of several processes as chitin catabolism and sesquiterpenoids biosynthesis, while no GO term enrichment was found with eggplant DEG.

The genes identified from S. torvum catalogue, bearing high similarity to known nematode resistance genes, were further investigated in view of their potential role in the nematode resistance mechanism.

Conclusions: By combining 454 pyrosequencing and microarray technology we were able to conduct a cost-effective global transcriptome profiling in a non-model species. In addition, the development of an in silico validation strategy allowed to further extend the use of the custom chip to a related species and to assess by comparison the expression of selected genes without major concerns of artifacts. The expression profiling of $S$. torvum responses to nematode infection points to sesquiterpenoids and chitinases as major effectors of nematode resistance. The availability of the long sequence tags in S. torvum catalogue will allow precise identification of active nematocide/nematostatic compounds and associated enzymes posing the basis for exploitation of these resistance mechanisms in other species.

Keywords: Torvum, Nematode resistance, 454 pyrosequencing, Microarray, Heterologous hybridizations

\footnotetext{
* Correspondence: emidio.sabatini@entecra.it

${ }^{5}$ Consiglio per la Ricerca e la Sperimentazione in Agricoltura, Unità di Ricerca per l'Orticoltura, Monsampolo del Tronto, AP, Italy

Full list of author information is available at the end of the article
} 


\section{Background}

Solanum torvum Sw (hereafter Torvum) is worldwide employed as rootstock for eggplant cultivation because of its vigor and resistance/tolerance to heavy metal- and salt-contaminated soil and, specially, to the most serious soil-borne diseases (i.e. bacterial, fungal wilts and rootknot nematodes) [1]. However, despite the fact that identification of the effectors of Torvum resistance would be extremely valuable for other solanaceous crops, particularly eggplant, very little studies have been conducted to date regarding Torvum resistance mechanism and have mainly dealt with its resistance to bacteria [2]. This scenario is mostly attributable to the paucity of database information on Torvum which, in turn is a consequence of the lack of high-throughput genomic tools (e.g. dedicated microarray SNP panels and genome sequencing)).

Few expression databases were available for Torvum. Only recently, 6,296 unigenes from Torvum cv. Torubamubiga, a low cadmium $(\mathrm{Cd}$ )-accumulating variety, have been obtained in the context of studies on $\mathrm{Cd}$ acclimation process [3]. This gene catalogue represents a significant improvement in terms of sequence information; however, given the current high-throughput standards, is unsuitable to pose the basis for global transcript profiling (e.g. to design probes for a comprehensive chip) due to its small size.

An approach to overcome such typical non-model species constraints would be undertaking an RNA-sequencing approach, since no prior knowledge of transcript sequences is mandatory. An alternative is represented by microarray hybridizations, a robust and well-assessed technique, about ten-fold less expensive per sample when compared to the cheapest RNA-Seq approaches [4]. Microarray can be considered as a viable alternative to RNA-Seq provided that the number of available sequences for the species of interest is considered satisfactory. Thus, in order to extend the number of probes for Torvum, we combined 454-based pyrosequencing with microarrays as reported by [5]. A further example of this strategy has been recently presented [6].

Root-knot nematodes, Meloidogyne spp. determine substantial losses on horticultural and field crops [7]. In the tropical and sub-tropical regions, crop production losses due to nematodes were estimated at $14.6 \%$ compared with 8.8\% in developed countries [8]. The American Phytopathological Society has reported that root-knot nematodes are the most common and destructive nematode pathogens, accounting for an estimated of $14 \%$ of all worldwide plant losses, which translates into almost \$ 100 billion dollars annually [9].

Meloidogyne incognita belongs to the order Tylenchida, a very large and diverse group of nematodes, which contains a majority of the known plant parasitic species. Representatives of this order have a worldwide distribution and are encountered more frequently than any other group of nematodes. Within Tylenchida, members of the family Heteroderidae are by far the most damaging to world agriculture, among which the root knot nematodes (RKN) (Meloidogyne spp.) and the cyst nematodes (Globodera spp. and Heterodera spp). To date, more than 80 RKN species are described, and M. incognita is unquestionably the most important one in terms of distribution and damages. Nematodes establish complex interactions with hosts, and, upon successful infection, cause the reprogramming of host cell developing structures as multinucleate giant feeding cells. More than 400 proteins have been found to be secreted by $M$. incognita [10] and several of these proteins are thought to play a role in modulating infection and reprogramming host metabolism.

Nematode Resistant (Nem-R) genes are an obvious topic of interest for crop protection. The first cloned Nem-R gene was the sugar beet Hs1pro-1 conferring resistance against the sugar beet cyst nematode [11]. However, Hs1pro-1 appears poorly related to typical plant $\mathrm{R}$ genes. Several other Nem-R genes (e.g. Mi-1, Hero A, Gpa2 and Gro1-4, all cloned from tomato or potato relatives) belong to the NBS-LRR class of R-genes [12]. With respect to the subclass of RKN R-genes (RKN-R), few resistance genes have been identified and only two have been cloned, namely Mi-1 from tomato [13] and, very recently, Ma from the Myrobalan plum Prunus cerasifera [14]. Both Mi-1 and Ma confer broad-spectrum resistance against several root knot nematode. Not only a single pathogenrelated gene in response to nematodes attack is described in the literature. More than one major gene is often involved in the resistance mechanisms commonly referred as horizontal resistance.

Wang et al. [15] identified one major recessive gene with strong additive effect against $M$. incognita in cotton, together with a major QTL with strong dominant effect in different crosses using different resistance sources. Transgressive segregation was previously documented from the same authors [16] as an epistatic interaction that strengthened the resistance phenotype. The determinants of Torvum resistance to nematodes are yet to be identified, and, in particular, the contribution of a specific gene-for-gene interaction rather than an horizontal, quantitative resistance, or even a "non-host" resistance phenomena (or a combination of these mechanisms) is far from being clear.

A number of studies have investigated transcriptional changes of $M$. incognita-challenged compatible and incompatible plants in a variety of species. Two early studies described the transcript profiling of about 900 transporter genes in A thaliana [17] and of 1,547 selected genes in tomato [18]. The latter work was carried out on resistant and susceptible tomato genotypes and, by comparing transcript abundance patterns over a time-course, 
several clusters of genes associated to compatible and incompatible interactions were accurately defined. Furthermore, a glycosyltransferase was shown to be necessary for conferring the resistant phenotype [18].

A larger number of genes $(22,089)$ was tested by Jammes et al. [19] in Arabidopsis, using giant cell-enriched root tissues infected by $M$. incognita along three timepoints. About 3,000 genes were called as differentially expressed between uninfected root tissues and galls at different developmental stages. Major classes of modulated genes included metabolism-associated genes and transcription factors. A substantial down-regulation of defense genes, including phenylpropanoids, was found.

More recently [20], the expression profiling of about 2,000 genes from EST libraries obtained from $M$. incognita-challenged resistant and susceptible cotton varieties, revealed differential modulation in resistant and susceptible genotypes of genes falling in the broad categories of pathogen recognition, signal transduction and pathogen defense. This latter category included superoxide dismutases, chitinases and isoflavone reductases. A further recent work [21] have described the changes in the soybean transcriptome using the Affymetrix ${ }^{\circledR}$ Soybean Genome Array (37,500 genes) in galls formed in M. incognita-challenged roots at 12 days and 10 weeks after infection. Genes encoding enzymes involved in carbohydrate and cell wall metabolism, cell-cycle control and plant defense were significantly modulated. Among plant defense genes, several lipoxygenases, pathogenesisrelated proteins and phenylpropanoid genes were found to be differentially expressed.

The aim of this work was, by global transcriptome profiling, getting insights on the mechanisms underpinning Torvum resistance against $M$. incognita. Toward this end, we deployed an approach which takes advantage of both Next generation sequencing (NGS) and microarray techniques. In particular, we targeted previously uncharacterized transcripts by RNA-Seq and exploited reliability and cost-effectiveness of well established microarray technologies for transcript quantification. We also explored the "chip extension" procedure, an approach allowing to increase the reliability of heterologous hybridizations by defining subset of probes less likely to be prone to expression artifacts. The availability of a 3 ' transcript catalogue for Torvum and transcript profiling upon nematode infection provides molecular tools for identifying Torvum resistance mechanism.

\section{Results and discussion} De novo assembly

Since only 6,296 unigenes from Torvum are available to date [3], we undertook an RNA-Seq pyrosequencing approach (454-GS-FLX technology with Titanium chemistry) to extend the number of Torvum genes and thus pose the basis to perform a global transcriptome profiling in a cost-effective manner. According to [5] we produced a comprehensive normalized catalogue of the 3' mRNA regions (500-600 bp) tailored at the generation of a custom chip. As starting material, Torvum roots were subjected to a wide range of environmental stresses (see Materials and Methods) to maximize the number of expressed genes. Sequencing was confined to the 3' in order to: i) minimize the number of 454 reads mapping to the same transcript but assembling in different contigs due to the lack of uniform coverage in low-abundance transcripts (e.g. transcripts where reads do map towards 5 ' and 3' regions but not in intervening region of the same RNA molecule); ii) allow for designing highly specific probes by encompassing 3' regions which are known to be subjected to lower selection pressure. The library was normalized as this treatment has been shown to greatly improve rare transcript coverage as well as other quality features [5]. One-quarter of the 454 plate was used to sequence the normalized 3'cDNA library yielding 205,591 reads with an average length of 356 bases for a total of (trimmed and quality-filtered) 73,266,807 bases.

Assuming an average number of transcripts of 30,000 with an average length of $2 \mathrm{~Kb}$ and thus a transcriptome length of $60 \mathrm{Mb}$, an yield of $73 \mathrm{Mb}$ confined to 500-600 bp at the 3' regions represents a coverage of about $4 \mathrm{x}$. This coverage, while not exhaustive, poses the basis, at least within the context of a normalized library, for quantification of a high number of transcripts in comparison to the few thousands of unigenes to date available for Torvum.

De novo assembly of Torvum reads was undertaken with MIRA 3.0.5 [22]. The assembly led to 24,922 contigs plus 11,875 singletons (Table 1). Various parameters including N50 were calculated to describe the average size of the contigs. In Additional file 1, the distribution of contig length (panel a) and contig coverage (panel b) is shown. As a consequence of our 3' sequencing design, the most

Table 1 Summary of Torvum assembly

\begin{tabular}{lc}
\hline Total reads & $\mathbf{2 0 5 . 5 9 1}$ \\
\hline$N^{\circ}$ of reads assembled & 161.636 \\
$N^{\circ}$ of singlets & 11.875 \\
Contigs & 24.922 \\
Total unigenes (contigs plus singletons) & 36.797 \\
Discarded reads & 43.955 \\
N10 contig size & 715 \\
N25 contig size & 627 \\
N50 contig size & 514 \\
N90 contig size & 386 \\
N95 contig size & 327 \\
\hline
\end{tabular}


enriched bin for unigenes (contigs plus singletons) was, as expected, in the 500-600 bp region. Contig coverage (average number of reads per contig) was relatively uniform as a result of the normalization step [5].

To further assess the assembly, we compared the contigs plus singletons (hereafter referred to as Torvum unigenes) against selected public assemblies, including the recently released 6,296 unigene catalogue from Solanum torvum cv. Torubamubiga [3]. Further queried databases (as detailed in Materials and Methods) were the current releases in TC database from the phylogenetically related species eggplant (25,443 unigenes), tobacco $(116,964)$, tomato $(52,502)$, potato $(62,330)$ and pepper $(32,399)$. At last, we tested Arabidopsis (112,827 unigenes) as a phylogenetically distant reference. As expected, a limited number of Torvum queries showed hits against the small (6,296 unigenes) Torvum Torubamubiga dataset (about $40 \%$ of queries at $\mathrm{E} 10^{-6}$ ), while the larger TC solanaceous datasets as potato, tomato, eggplant and tobacco exhibited between 70 and $80 \%$ hits. However, when these results are corrected for the number of entries of the queried databases (percent hits divided by number of entries in queried database), eggplant and $S$. Torvum cv. Torubamubiga clearly emerged as the most correlated to Torvum database. On the other hand, the phylogenetically distant species Arabidopsis shows a barely detectable ratio of percent hits to database extent (data not shown).

Overall, the blast data closely mirror known phylogenetic relationships within solanaceous species [23,24] with Torvum having its closest counterpart in eggplant and, in order of decreasing relatedness, potato, tomato, pepper and tobacco. Noteworthy, at an Expect value of $10^{-6}$, more than $60 \%$ of Torvum unigenes had no hits against cv. Torubamubiga database, indicating that a majority of Torvum unigenes in our catalogue are not represented in the small Torubamubiga dataset (6,296 unigenes). On the other hand, when Torubamubiga database was queried against our Torvum unigene catalogue, only $18 \%$ of the 6,296 Torubamubiga unigenes had no hits, indicating that our Torvum transcript tags catalogue is likely to represent the most complete dataset for Torvum available to date.

\section{Custom chip design}

OligoArray 2.1 software [25] was used to compute gene-specific oligonucleotides corresponding to Torvum unigenes. OligoArray output, besides microarray design, provides hints on the quality (e.g. degree of redundancy) of input sequences by declaring how many specific probes can be designed based on input sequences. About $80 \%$ of oligos (30,162 out of 36,797 unigenes) turned out to be specific for one Torvum unigene, while 15\% oligos were specific for 1-3 unigenes, (Additional file 2) indicating efficient normalization and substantial lack of redundancy in the Torvum unigene set. A final filtering step over Torvum unigenes was conducted to exclude the less specific probes (i.e., those corresponding to unigenes for which oligoarray could not design a strictly specific probe and would thus hybridize with more than one target). This also allowed to contain the number of probes in the chip to maximum 30,000 , consistent with a triplicate probe layout in the 90k-features Combimatrix chip design. The final layout consisted in 24,394 probes representative of contigs and 5,606 probes derived from singletons. The significant reduction (more than 50\%) of singleton representation in the final chip layout likely reflects the constraints experienced by oligoarray software in designing specific probes for singletons due to the shorter length and/or lower qualities of sequences when compared to contigs.

\section{Differentially expressed genes in nematode-infected Torvum}

Two-months-old Torvum plants were infected with Meloidogyne incognita and left to proceed for 14 days. Neither root-galls (RG) nor egg-masses (EM) were never collected on Torvum stained root $(\mathrm{RG}$-index $=0, \mathrm{EM}=0$ ) even in longer infection stages (60 dpi).

Torvum RNA samples (three biological replicates for both control and inoculated roots) were used for array hybridizations. Pearson correlation coefficients for biological replicates were all above 0,85 (Additional file 3). Genes were considered differentially expressed if exhibiting at least a 2 -fold change and a False Discovery Rate $($ FDR $)<=0.1$. Figure 1 depicts transcript abundance values in control vs. infected roots as MA-plot. Differentially expressed genes (DEG) fulfilling the two criteria (390 genes) are plotted in red. The full list of DEG accompanied by expression ratio, FDR values, blast hits, Blast2GO annotations and GO mappings are reported in Additional file 4.

\section{Annotation of Torvum gene catalogue}

The software suite Blast2GO [26] was used to annotate Torvum unigenes. As a first blast step, we run BlastX against NCBI non-redundant database using as query the 23,284 unigenes included in the chip layout for which an hybridization signal could be obtained. A total of 71,474 GO annotations were retrieved. The full catalogue of Torvum genes including Blast2GO annotations and complementary information (i.e. blast hit description for transcripts below Blast2GO annotation threshold) are available in Additional file 5, while the full set of Torvum unigene sequences (ID of contigs plus singletons and transcript sequences) is provided in fasta format in Additional file 6.

\section{Go enrichment analysis of torvum DEG genes}

Major expression trends in infected Torvum were investigated to test whether the 390 DEGs could be grouped 


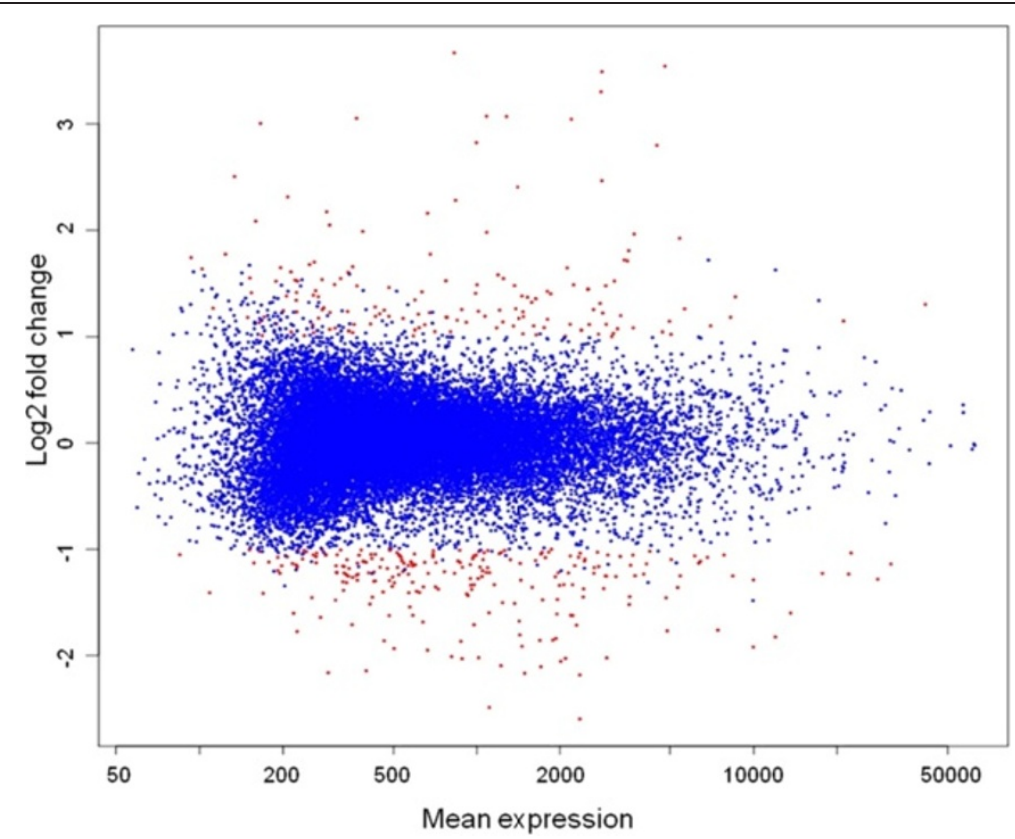

Figure 1 Overview of Torvum transcriptional changes upon nematode infection. The MA-plot represents mean expression values plotted versus $\log 2$ fold changes. Called DEGs (fold change $>2$ and FDR $<0.1$ ) are plotted in red.

in some enriched GO terms. Towards this end, we used as a reference set the 12,344 annotations obtained with Blast2GO and as test set the 390 DEGs. The Fisher's exact test results $(\mathrm{FDR}<=0.1)$ for the entire set of enriched GO terms and corresponding Torvum unigenes is reported in Additional file 7. In Figure 2, the most specific enriched terms are combined in a chart. Among enriched GO terms, several fall within a generalized biotic stress, namely "cell wall macromolecule metabolic processes", "extracellular region", "response to stress", "polysaccharide catabolic process" and "response to fungus". Further enriched GO terms, including chitin and isoprenoid -associated processes appear of special interest within the context of nematode infection and will be analyzed in more detail.

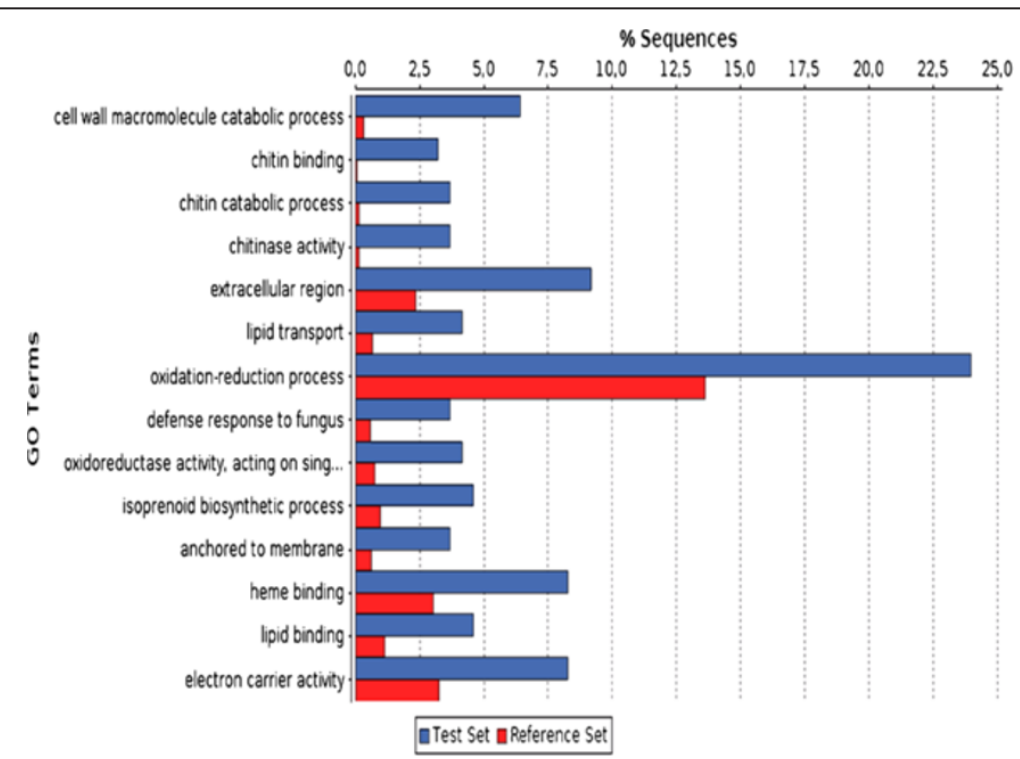

Figure 2 GO term enrichment. The most specific GO terms enriched in Torvum as a consequence of infection are shown. For each GO term, the percentages of Torvum unigenes in test set (DEG) or reference set (total annotated unigenes) are reported. 


\section{Chip-extension to eggplant}

While the focus of this study was to investigate Torvum defense responses upon nematode infection, we reasoned that the custom chip designed in this work may as well provide valuable complementary information concerning eggplant, a phylogenetically close, nematodesusceptible species. Eggplants are most seriously affected by Meloidogyne, when plants of the breeding line 1F5(9) were infected with root knot nematodes a very high susceptibility with RG-index $=5$ and EM $=5$ was scored. To our knowledge, no genome-wide expression studies have been published to date for nematodechallenged eggplant.

Heterologous hybridizations are based on interrogation of a chip specifically designed for a species (primary species) with transcripts from a phylogenetically-related species (secondary species). Heterologous hybridizations have in many cases shown to be valuable resources for non-model species, especially when the primary and secondary species are closely related ([27-29] and references therein). Furthermore, in recent years, validation procedures have been developed allowing the definition in the secondary species of subsets of probes where expression data are predicted to be highly reliable [27]. These procedures exploit the fact that the probes designed for a primary species (i.e. generally perfectly matching to primary species transcripts) can be tested for matching to database transcripts of a secondary, interrogating species. This allows assessment of expression data reliability and eventually definition of subsets of genes in the secondary species which can be evaluated with reduced concerns of expression artifacts.

To validate the heterologous expression data, we followed an approach conceptually similar to that presented in Bagnaresi et al. [27]. Toward this end, we first pooled several expression (EST and assembled unigenes) eggplant databases and queried the merged eggplant database with Torvum chip probe sequences using local BlastN at a relaxed stringency. Alignment results were parsed to filter probes based on alignment parameters expected to influence hybridization strength. The following parameters were considered (see explanatory Figure 3): i) ratio of alignment length to oligo length (percent alignment); ii) maximum number of mismatches; and iii) distance from the start of oligo/transcript alignment to oligo 5' end. The rationale for the choice of these parameters is based on data presented in Additional file 8. The mean of all expression values (both control and infected conditions, Additional file 8, panel A) for all 23,284 probes (i.e. no filtering) was 945 (727 when considering only probes with an alignment $<=40 \%$; data not shown). When probes are selected by filtering with the above parameters, the mean of all expression values reaches the maximum for probes filtered for percent

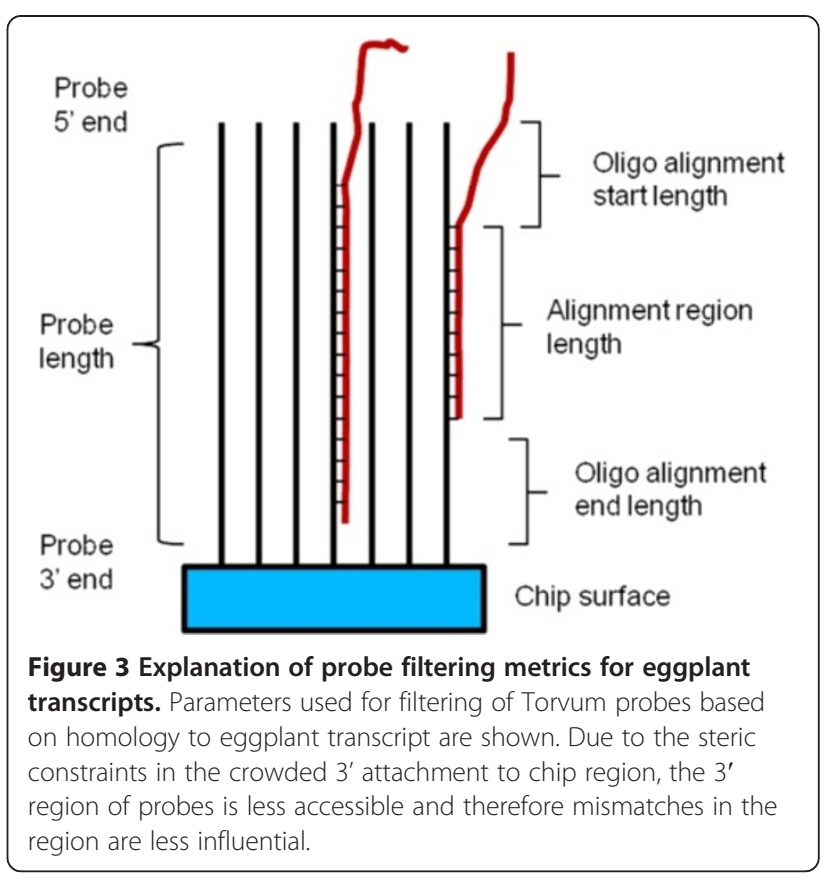

alignment $=100 \%$ and 0 mismatches $(808$ probes conserved; mean hybridization value 2,424) (Additional file 8 , panel A). On the other hand, when less stringent values were tested, down to the very relaxed >= $30 \%$ alignment and up to 3 mismatches, mean expression values drop to about 900 (23,284 probes conserved) (Additional file 8, panel A). This variation in expression values is consistent with the fact that, when the homology between chip oligos and eggplant transcripts is high, high hybridization values are detectable. Additionally, the influence of the distance between the starting point of oligo alignment and the respective Blast hit within $5^{\prime}$ end was monitored (Additional file 8, panels $\mathrm{B}$ to E). In fact, oligos are attached to the chip in the 3' side and this causes steric hindrance in the crowded 3' regions to interfere with hybridization [30]. Therefore, poor homology along oligo 3' region against interrogating transcripts can be expected to be less influential on hybridization intensity, as confirmed in our data No effect could be detected when selection was made for distance of alignment from 3' side (data not shown). We further checked that the variation in mean hybridization is not a mere consequence of the varying number of probes filtered at the different imposed stringencies. A plot where a number of random probes corresponding to the number of probes resulting by setting stringency conditions is shown in Additional file 8F. As expected, no meaningful variation in signal strength is detectable in this case, ruling out that simply the number of probes, irrespective of probe $v s$. interrogating sequence homology, is influential. All these observations are summarized in Additional file 8, where percent alignment, number of 
mismatches within the alignment and oligo alignment start position are plotted versus mean hybridization values and number of retained probes.

Based on the above data, in order to define an high confidence pool of probes for eggplant, we selected a reasonable tradeoff between stringency and number of preserved probes: i) ratio of alignment length to oligo length $>=0.6$; ii) maximum number of mismatches $<=2$; iii) start of oligo alignment within the first 20 bases from 5 ' oligo end. These parameters lead to 5,770 retained oligos with a mean signal of 1,525 , a value well above the mean of 727 obtained when only probes with an alignment $<=40 \%$ were considered (data not shown) and is still higher than 945 , the mean of all probes in the chip (Additional file 8A). To finally verify that our probe validation procedure was beneficial, we computed the Pearson's product moment correlation values for eggplant samples. The correlation increased in most cases (14 out of 15 pair wise comparisons) when comparing validated versus total probes (Table 2 and Figure 4) as expected by removal of probes where, due to the absence of a matching transcript target, random noise prevails leading to inconsistencies among replicates [29].

\section{Overall comparison between Torvum vs. eggplant DEGs}

As for Torvum samples, eggplant total RNA samples were extracted from control and 14-d inoculated roots (three biological replicates for each condition) and used for array hybridization. In contrast with Torvum, numerous galls and egg-masses were visible in eggplant at the end of the infection process confirming a successful establishment of the infection and reproduction. DEGs calling using the same values as for Torvum (FDR $<=0.1$ and fold change $>=2$ ) resulted in 1,217 genes over the entire 23,284 chip gene set, a value approximately 3 -fold larger than found for Torvum genes (Additional file 9). When the 5,770 validated genes were considered, 250 eggplant DEGs were obtained. Thus, 5.2 and 4.3\% DEGs were respectively obtained if the validated or total gene sets are chosen. Only 43 and 13 of these eggplant DEG were in common with Torvum DEGs for total and validated dataset, respectively (data not shown).

We further conducted GO enrichment analysis with both the raw and validated eggplant dataset. For validated dataset, prior to Fisher's test, non-validated genes were subtracted from test and reference sets. No enriched GO terms were revealed using either total or validated dataset.

Eggplant responses to infection at $14 \mathrm{dpi}$ appear to involve modulation of a substantial amount of genes whose large majority is distinct from Torvum DEGs. Furthermore, such modulation appears more sparse and heterogeneous as indicated by a lack of GO enrichment. This scenario is likely attributable to successful infection in eggplant as well as to the late infection stage monitored (14 dpi). In fact, it is expected that wide gene modulation (as distinct from Torvum incompatible interaction) occurs due to the establishment of infection in eggplant. Indeed, compatible interaction involves complex rearrangements as development of multinucleate feeding sites, reallocation of nutritional resource to fulfill pathogen needs, root-galling circuitry and further morpho-physiological alterations to cope with enzymerich nematode secretions [31,32]. Indeed, more DEGs

Table 2 Correlation values among eggplant samples prior or after validation

\begin{tabular}{|c|c|c|c|c|c|c|}
\hline \multicolumn{7}{|c|}{ Validated genes (5770 genes) } \\
\hline & Mel1_ctrl & Mel2_ctrl & Mel3_ctrl & Mel1_infected & Mel2_infected & Mel3_infected \\
\hline Mel1_ctrl & 1 & & & & & \\
\hline Mel2_ctrl & 0.93623 & 1 & & & & \\
\hline Mel3_ctrl & 0.92142 & 0.96054 & 1 & & & \\
\hline Mel1_infected & 0.96322 & 0.94946 & 0.92652 & 1 & & \\
\hline Mel2_infected & 0.93271 & 0.94647 & 0.93664 & 0.97194 & 1 & \\
\hline Mel3_infected & 0.89345 & 0.94810 & 0.95296 & 0.94982 & 0.95941 & 1 \\
\hline \multicolumn{7}{|c|}{ ALL GENES (23284) } \\
\hline & Mel1_ctrl & Mel2_ctrl & Mel3_ctrl & Mel1_infected & Mel2_infected & Mel3_infected \\
\hline Mel1_ctrl & & 0.92705 & 0.91702 & 0.93579 & 0.91434 & 0.88157 \\
\hline Mel2_ctrl & 0.92705 & & 0.95298 & 0.92503 & 0.92737 & 0.93377 \\
\hline Mel3_ctrl & 0.91702 & 0.95298 & & 0.91714 & 0.92448 & 0.94053 \\
\hline Mel1_infected & 0.93579 & 0.92503 & 0.91714 & & 0.96931 & 0.95660 \\
\hline Mel2_infected & 0.91434 & 0.92737 & 0.92448 & 0.96931 & & 0.95889 \\
\hline Mel3_infected & 0.88157 & 0.93377 & 0.94053 & 0.95660 & 0.95889 & \\
\hline
\end{tabular}

Pearson's product moment correlation values for eggplant samples are compared. 


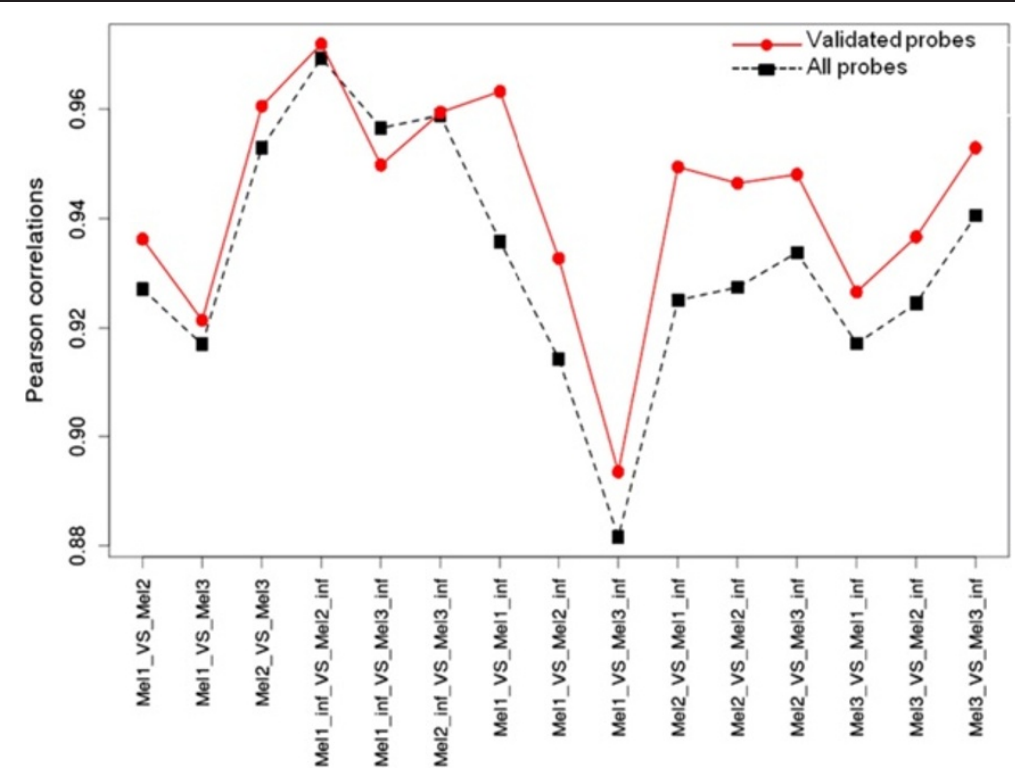

Figure 4 Pearson correlations among eggplant samples using total vs. validated probes. Pearson's product moment correlation for eggplant samples were computed for the entire set of probes or the subset of eggplant validated set of probes. Correlations are shown for all pairs of sample combinations.

were found in compatible vs. incompatible interaction of Meloydogine spp. in cowpea hosts [28]. The lack of GO enrichment for eggplant DEG as opposed to Torvum DEG may reflect a more targeted response of Torvum genes towards activation of specific defense responses against nematodes.

In the following sections, the heatmaps of expression data where Torvum and eggplant are compared include the information of eggplant validation (probes boxed in red). This allows to evaluate eggplant expression data with additional reliability hints based on the existence in eggplant databases of a transcript with satisfactory homology to Torvum probes. It should be stressed, however, that the absence of a validated probe for eggplant may also indicate that the expression of this gene is Torvumspecific; alternatively, the gene may be expressed at very low levels in eggplant causing its absence in expression repositories. Both of these information may be valuable to pinpoint Torvum-specific expression responses.

\section{Chitinases}

As shown in the bar chart in Figure 2, chitin binding, chitin-catabolic process and chitinase activity are enriched GO terms in Torvum DEGs. Figure 5 depicts an heatmap of the 25 Torvum genes annotated with the GO term 'chitinase activity' (GO ID = GO:0004568). Eight of these 25 genes are modulated in Torvum (ID boxed in black). Six of these are induced by infection and cluster together (pink sidebar). Intriguingly, only one probe (namely tor5_C8583, corresponding to class II chitinase) is among eggplant validated probes. This finding, while inviting caution on eggplant expression data for this cluster, indicates that, to date, no other transcripts have been reported for eggplant in this cluster suggesting that these genes might be absent or expressed at very low levels in eggplant. Thus, those chitinases may represent a group of nematode-responsive genes whose presence and/or inducibility recruitment is an exquisite feature of nematode-challenged Torvum.

Chitinases have long been known to be involved in defense responses against nematodes ([33,34] and references therein). In particular, soybean cultivars exhibiting enhanced resistance to $M$. incognita displayed earlier induction and higher overall chitinase activity when compared to susceptible cultivars [35]. Furthermore, chitinases transcripts have been found to be upregulated in transcript profiling experiments of $M$. incognita-challenged cotton roots [20] Although only the egg shell of nematodes contains chitin as a constituent, chitinases may interfere with nematode vitality at various stages of infection [33]. These previous findings have prompted transgenesis approaches aiming at introducing exogenous chitinase in crops. In preliminary attempts with chitinases from Manduca sexta [36] and the fungus T. harzianum [37], chitinases did not provided enhanced resistance to nematodes when introduced in soybean and tobacco, respectively. This may indicate that native, specific chitinase isoforms and/or appropriate conditions (e.g. tissue-specific expression) as experienced by the native chitinases may be required to exert nematode protection activity. For example, concomitant action of protease may be required to effectively disrupt nematode chitin [38]. More recently, an active chitinase, 

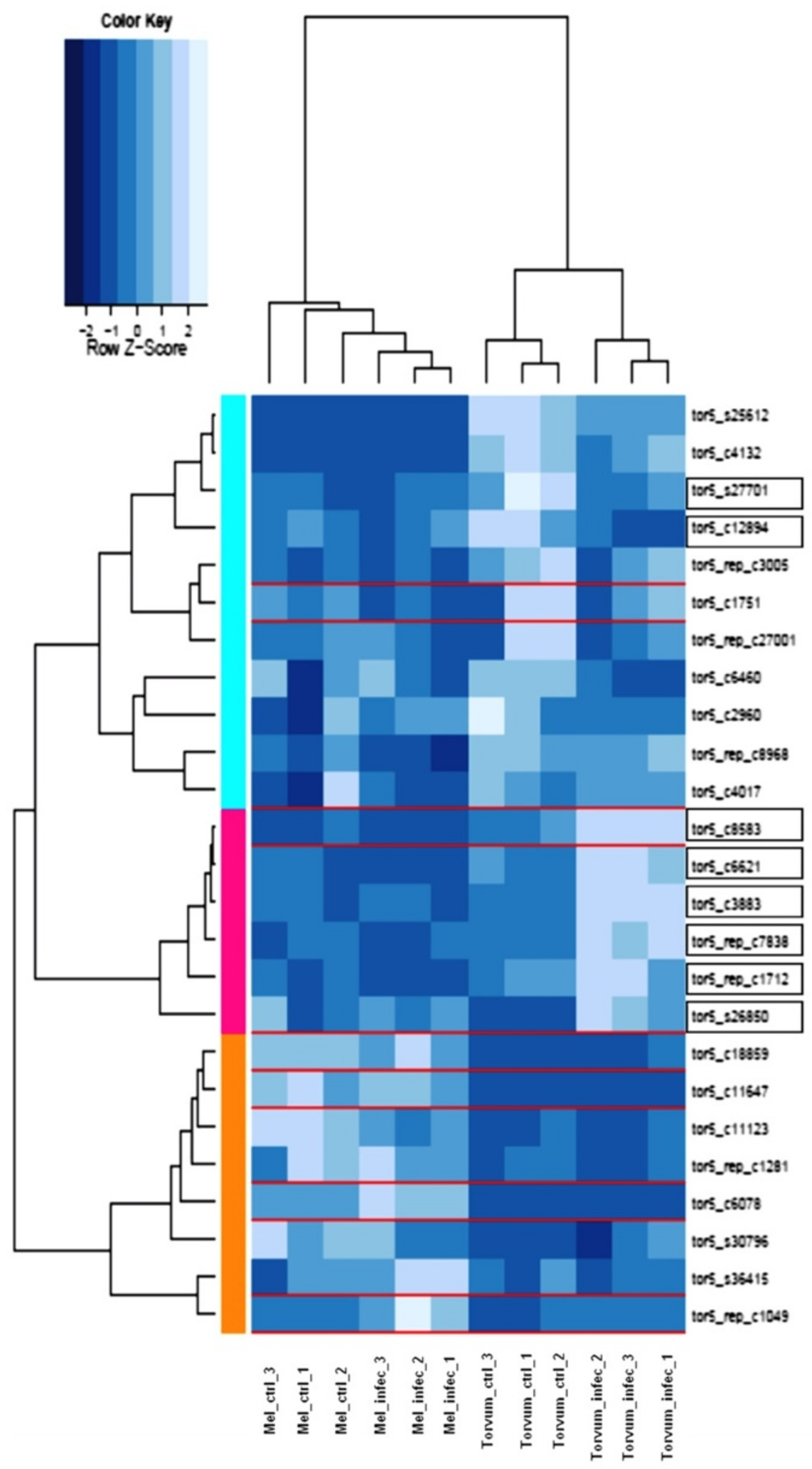

Figure 5 (See legend on next page.) 
PjCHI-1, has been identified in Paecilomyces javanicus, a non-nematophagous fungus. When expressed in tomato, PjCHI-1 has been shown to reduce egg masses and repress the embryonic development of $M$. incognita $[39,40]$. PjCHI-1 belongs to class $\mathrm{V}$ of chitinase family 18 [35] and, intriguingly, tor5_c6621 shows as best blast hit tobacco class V chitinase (CAA54373). Details on induced Torvum chitinases are listed in Table 3. Induced chitinases (from 4- to 2-fold) appear to belong to distinct classes, probably reflecting that efficient chitinase activity may require a pool of various chitinase classes acting in concert. Identification at the sequence level of Torvum nematodeinduced chitinase may thus help to narrow down the choice of chitinase isoforms to effective ones for introgression into susceptible crops.

\section{Sesquiterpene biosynthetic enzymes}

GO analysis of torvum DEGs revealed an enrichment for 'isoprenoid biosynthetic process' term (GO:0008299). Figure 6 provides an overview of expression pattern of 131 Torvum genes annotated with this term. Noteworthy, Torvum samples cluster together, while eggplant samples (despite several validated genes boxed in red) appear to respond less coherently, as control and infected samples do not cluster together. Figure 7 details expression patterns for the 10 modulated Torvum genes (eggplant validated counterparts boxed in red), while fold change data and the top blast hit for each of the modulated genes are reported in Table 4. Intriguingly, within this group of 'isoprenoid biosynthetic process' DEGs, sesquiterpene and diterpenoid biosynthetic genes undergo opposite modulation, i.e. induced the former and repressed the latter. In plants, diterpenes (20C, 4 isoprene units) are produced via the plastid pathway (MEP/DOXP pathway), whereas sesquiterpenes (15C, three isoprene units) derive from cytosolic mevalonate pathway [41]. Based on Blast2GO annotation and BlastX hits as reported in Table 5, tor5_c9415 encodes for a cytP450 enzyme with as best hits several CYP450, including epi-aristolochene 1,3 dihydroxylase and premnaspirodiene oxygenase (Cyt P450 71D55) [42]. This P450 enzyme catalyzes several hydroxylations for sesquiterpene substrates including phytoalexins as solavetivone. In turn, tor5_rep_c18585 and tor5_rep_c114 show both as best hit sesquiterpene synthase 2, while tor5_c8884 shows as best hit potato vetispiradiene synthase. The tor5_rep_c2244 (best hit 3-hydroxy-3methylglutaryl CoAa reductase; HMGR) and tor5_c9415 (best hit cytochrome p450) are the only two genes within Torvum DEGs present in the validated eggplant dataset although they are not differentially expressed. HMGR plays a critical role in isoprenoid biosynthesis as catalyzes the first committed and rate limiting step in isoprenoid biosynthesis [43]. Thus, its presence in validated eggplant is a bona fide comparative clue towards the fact that the isoprenoid biosynthetic pathway is not up-regulated (at least at transcriptional level) following nematode infection in eggplant.

While an in-depth understanding of sesquiterpenoids biochemical reactions undergoing in nematode-challenged Torvum will require obtaining full-length transcripts from the Torvum transcripts, which in our dataset are limited by design to the 3' region, the fact that the biosynthetic sesquiterpenoid pathway is stimulated points to sesquiterpenoids as critical effectors of Torvum resistance mechanisms. Sesquiterpenoids include several compounds of well-established nematotoxic and nematostatic effects as gossypol, solavetivone, rishitin and lubumin [44], and references therein. Gossypol is a very effective sesquiterpene aldehyde shown to cause resistance to Meloydogine incognita $[45,46]$ in cotton and solavetivone, rishitin and lubumin are bicyclic sesquiterpenoids expressed in solanaceous species as tomato and potato capable of causing nematostatic effects [31,33]. High content of solavetivone (associated to the H1 resistance gene) was found to be critical for conferring resistance to Globodera rostochiensis [47]. Rishitin was shown to be induced by plant-parasitic nematodes and higher rishitin contents in various potato species were associated to higher nematode resistance. In particular, the action of rishitin or of a rishitin-like compound causing nematode to migrate away from plants, would be consistent with observed the poor establishment on parasites on Torvum plants [48].

It should be noted, however, that a substantial number of plant phytochemicals exhibit antinematodal activity and that evidence on the antinematodal activity of sesquiterpenoids is largely based on in vitro studies $[31,33,44,45]$. Few studies monitored the accumulation of sesquiterpenoids upon elicitation and, in only a subset of them, as in cotton roots [45], elicitation was driven by $M$. incognita infection, more frequently, general and unspecific elicitors as arachidonic acid were employed. A further work based on six cotton cultivars, did not support a correlation between resistance and sesquiterpenoid content [46]. Nevertheless, it should be noted that in the above mentioned elicitation studies, 
Table 3 Blast results of modulated transcripts grouped in GO term 'chitinase activity'

\begin{tabular}{|c|c|c|c|c|c|c|c|}
\hline ID & Blast2GO annotation & Length & Best hit desc. & Conserved domains & Hit ACC & E value & Expr ratio (infected/control) \\
\hline Tor5_s26850 & Wound-induced protein win2 & 443 & $\begin{array}{l}\text { Gi|19962|emb|CAA41437.1|pathogenesis-related } \\
\text { protein 4A [Nicotiana tabacum] }\end{array}$ & Barwin family pfam 00967 & CAA41437 & 5.87E-036 & 3.94 \\
\hline Tor5_c3883 & Wound-induced protein win1 & 644 & $\begin{array}{l}\text { Gi|19962|emb|CAA41437.1|pathogenesis-related } \\
\text { protein 4A [Nicotiana tabacum] }\end{array}$ & Barwin family pfam 00967 & CAA41437 & $6.97 \mathrm{E}-083$ & 3.96 \\
\hline Tor5_c8583 & Class ii chitinase & 568 & $\begin{array}{l}\text { Gi|544010|sp|Q05540.1|CHIB_SOLLC RecName: } \\
\text { Full=Acidic } 27 \text { kDa endochitinase; Flags: } \\
\text { Precursor >gi|19187|emb|CAA78844.1| chitinase } \\
\text { [Solanum lycopersicum] }\end{array}$ & $\begin{array}{l}\text { Glycoside hydrolase family } 19 \\
\text { chitinase domain }\end{array}$ & Q05540 & 7.18E-101 & 3.49 \\
\hline Tor5_c6621 & Class $\vee$ chitinase & 694 & $\begin{array}{l}\text { Gi|899342|emb|CAA54373.1|chitinase class V } \\
\text { [Nicotiana tabacum] }\end{array}$ & $\begin{array}{l}\text { Class V plant chitinases Glycosyl } \\
\text { hydrolase family } 18 \text { Specific hit } \\
\text { Cd02879 Superfamily cl10447 }\end{array}$ & CAA54373 & $1.52 \mathrm{E}-090$ & 2.55 \\
\hline Tor5_rep_c7838 & Class i extracellular chitinase & 669 & $\begin{array}{l}\text { Gi|21495|emb|CAA47921.1|chitinase } \\
\text { [Solanum tuberosum] }\end{array}$ & $\begin{array}{l}\text { Specific hit: Glycoside hydrolase } \\
\text { family } 19 \text { chitinase domain } \\
\text { (cd00325) Superfamily: lysozime } \\
\text { like domain (cl00222) }\end{array}$ & CAA47921 & 2.89E-094 & 2.24 \\
\hline Tor5_rep_c1712 & $\begin{array}{l}\text { Chia_tobac ame: full=acidic } \\
\text { endochitinase flags: precursor }\end{array}$ & 627 & $\begin{array}{l}\text { Gi|1 16332|sp|P29060.1|CHIA_TOBACRecName: } \\
\text { Full=Acidic endochitinase; Flags: Precursor } \\
\text { >gi|19775|emb|CAA77656.1| acidic chitinase III } \\
\text { [Nicotiana tabacum] }\end{array}$ & $\begin{array}{l}\text { Specific hit: cd02877 Superfamily: } \\
\text { GH18 Glycosyl hydrolase family } \\
18 \text { Cl10447 }\end{array}$ & P29060 & $6.82 \mathrm{E}-098$ & 2.03 \\
\hline
\end{tabular}




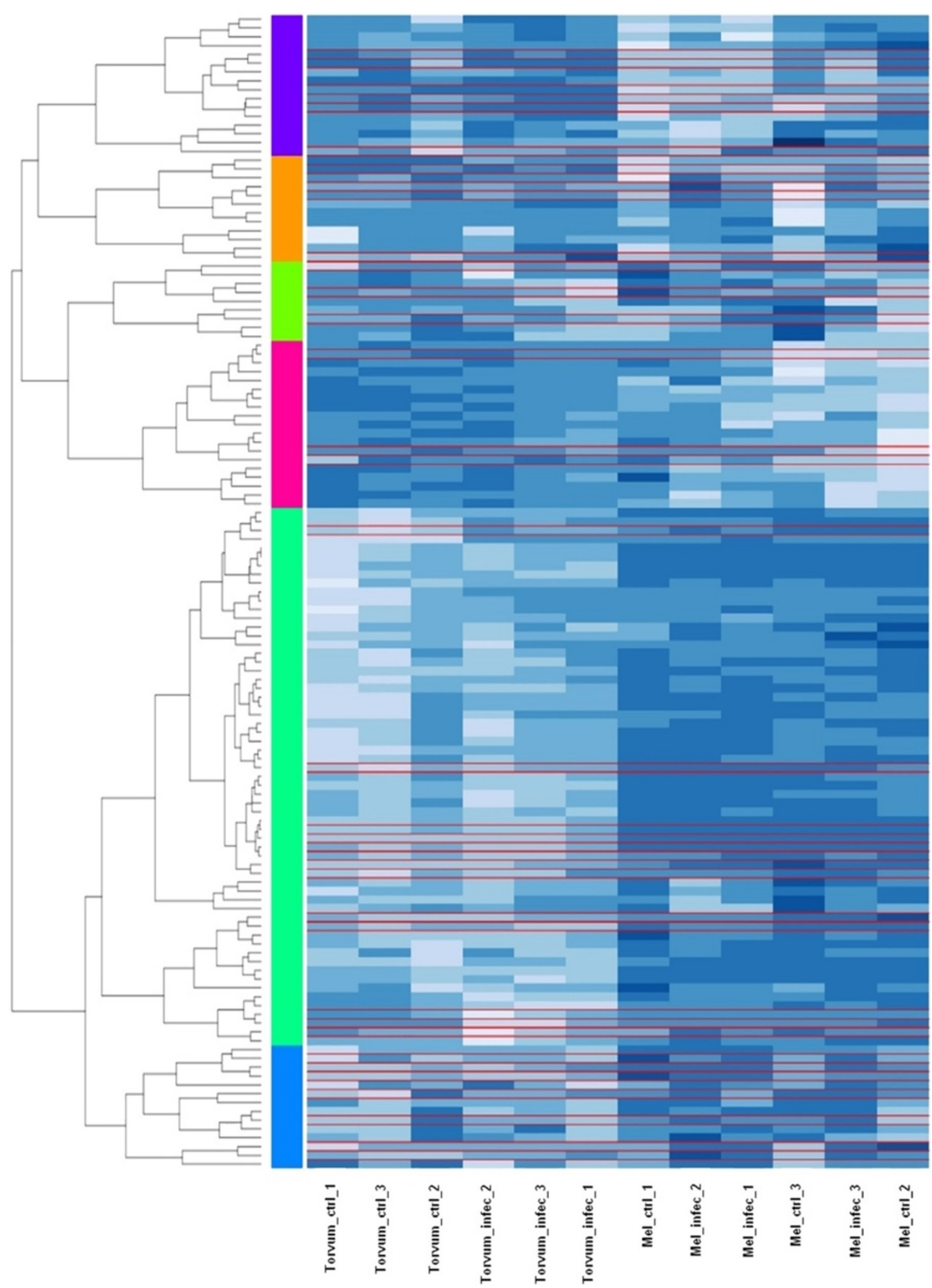

Figure 6 (See legend on next page.) 
(See figure on previous page.)

Figure 6 Heatmap of isoprenoid biosynthetic process transcript abundance. Overview of transcript abundance in Torvum and eggplant (torvum and mel prefix, respectively) as affected by M. incognita infection for the 131 members of GO class 'isoprenoid biosynthetic process' term (GO:0008299). Eggplant validated genes are boxed in red over the heatmap. Colored bars on the left of the heatmap mark distinct major branches in the clustering tree grouping genes with similar expression pattern. The color scale indicates the expression value (light blue indicate higher abundance value, darker blue indicates lower abundance values).

extraction and detection techniques were tailored to reveal a narrow range of compounds as low-molecular weight, non-polar chemicals $[45,47]$. This approach prevents and unbiased, global overview of the whole spectrum of defense strategies mounted by the host to counteract infection, and thus hampers an assessment of their relative contribution to actual resistance.

Prior to our report, no large-scale transcriptional profiling of $M$. incognita-infected resistant $v$ s. susceptible genotypes, had revealed transcriptional induction of

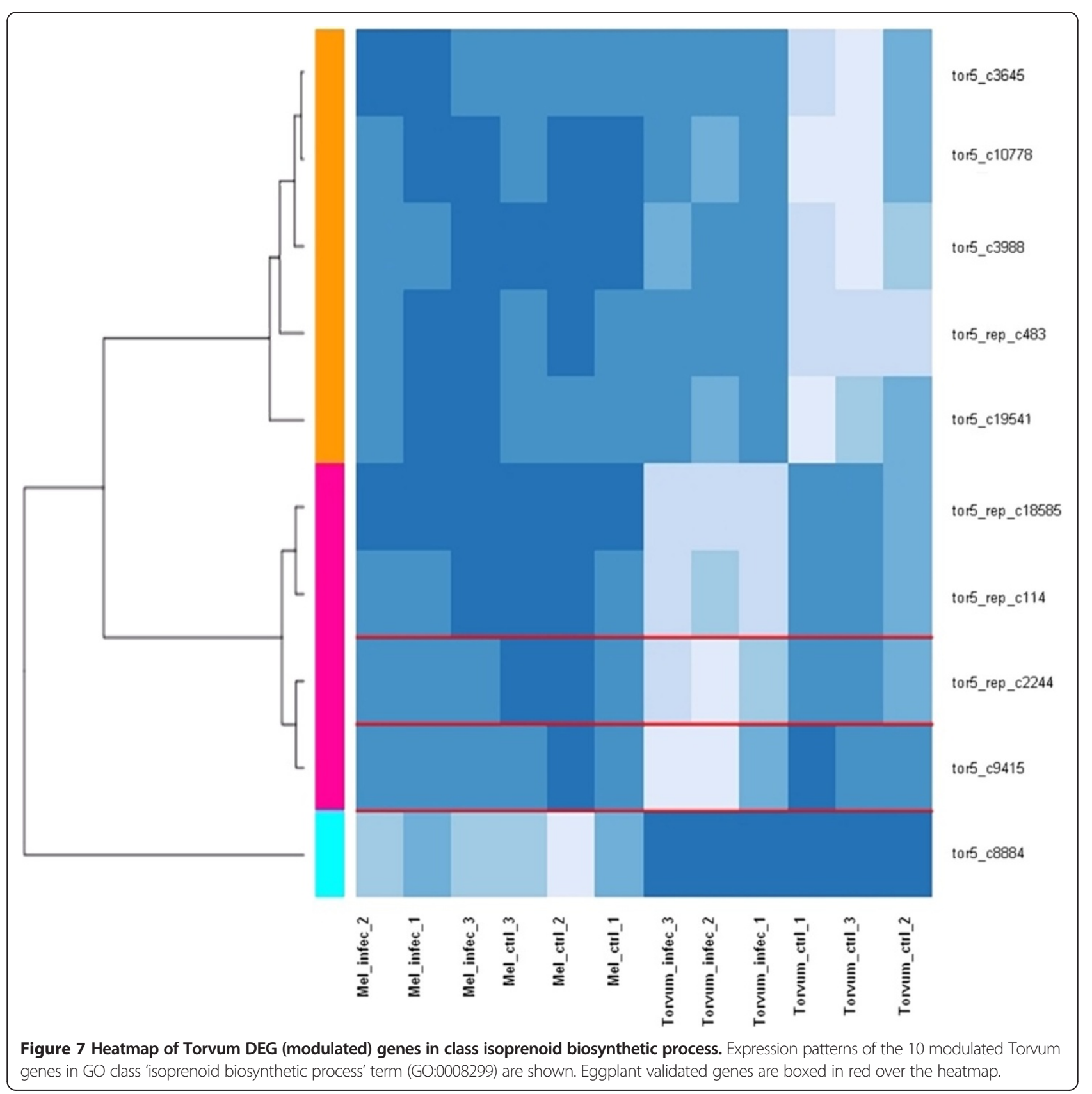




\section{Table 4 Blast results for modulated isoprenoid biosynthetic process transcripts}

\begin{tabular}{|c|c|c|c|c|c|c|c|}
\hline ID & $\begin{array}{l}\text { Fold change } \\
\text { (infected vs ctrl) }\end{array}$ & FDR & Blast2GO annotation & Hit description & Hit E value & Hit max identity (\%) & Hit accession \\
\hline Tor5_c9415 & 5.30 & 0.000627 & Cytochrome p450 & $\begin{array}{l}\text { Cytochrome P450 71D7 >gb|AAB61965.1| putative } \\
\text { cytochrome P450 [Solanum chacoense] }\end{array}$ & $3.00 \mathrm{E}-061$ & 100.0 & P93531.1 \\
\hline Tor5_rep_c18585 & 2.86 & 0.001475 & $\begin{array}{c}\text { Af279456_1 sesquiterpene } \\
\text { synthase } 2\end{array}$ & Terpene synthase [Solanum lycopersicum] & 4.0E-022 & 70.00 & AEP82784.1 \\
\hline Tor5_c8884 & 2.77 & 0.003101 & Vetispiradiene synthase & Vetispiradiene synthase [Solanum tuberosum] & $2.0 \mathrm{E}-116$ & 98.00 & BAA82141.1 \\
\hline Tor5_rep_c2244 & 2.39 & 0.005414 & $\begin{array}{l}\text { 3-hydroxy-3-methylglutaryl } \\
\text { coenzyme a reductase }\end{array}$ & $\begin{array}{l}\text { 3-hydroxy-3-methylglutaryl-coenzyme A reductase 2; } \\
\text { Short=HMG-CoA reductase } 2 \text { >gb|AAD28179.1|AF110383_1 } \\
\text { 3-hydroxy-3-methylglutaryl-coenzyme A reductase } \\
\text { [Capsicum annuum] }\end{array}$ & $1.00 \mathrm{E}-073$ & 99.00 & Q9XEL8.1 \\
\hline Tor5_rep_c114 & 2.37 & 0.026802 & $\begin{array}{c}\text { Af279456_1sesquiterpene } \\
\text { synthase } 2\end{array}$ & Terpene synthase [Solanum lycopersicum] & $2.00 \mathrm{E}-051$ & 73.00 & AEP82784.1 \\
\hline Tor5_rep_c483 & 0.49 & 0.00577 & Ent-Kaurene oxidase & Ent-kaurene oxidase [Pyrus communis] & 8.00E-055 & 75.00 & AEK01241.1 \\
\hline Tor5_c10778 & 0.48 & 0.038335 & $\begin{array}{l}\text { Copalyl diphosphate } \\
\text { synthase }\end{array}$ & $\begin{array}{l}\text { Copalyl diphosphate synthase [Solanum lycopersicum] } \\
\text { >dbj|BAA84918.1| copalyl diphosphate synthase } \\
\text { [Solanum lycopersicum] }\end{array}$ & 5.00E-049 & 72.00 & NP_001234008.1 \\
\hline Tor5_c19541 & 0.44 & 0.072615 & Gibberellin 2-oxidase & Gibberellic acid 2-oxidase [Capsicum annuum] & $1.00 \mathrm{E}-060$ & 84.00 & ABE98327.1 \\
\hline \multirow[t]{2}{*}{ Tor5_c3988 } & 0.38 & 0.057934 & $\begin{array}{l}\text { Geranylgeranyl } \\
\text { diphosphate synthase }\end{array}$ & $\begin{array}{l}\text { Geranylgeranyl pyrophosphate synthase } 1 \\
\text { [Solanum pennellii] }\end{array}$ & $3.00 \mathrm{E}-048$ & 92.00 & ADZ24718.1 \\
\hline & & & & $\begin{array}{l}\text { Uncharacterized protein LOC100790001 precursor } \\
\text { [Glycine max] >gb|ACU19728.1| unknown [Glycine max] }\end{array}$ & 7.00E-049 & 76.00 & NP_001242838.1 \\
\hline Tor5_c3645 & 0.35 & 0.007791 & Cytochrome p450 & $\begin{array}{l}\text { Taxane 13-alpha-hydroxylase [Medicago truncatula] } \\
\text { >gb|AET00449.1| Taxane 13-alpha-hydroxylase } \\
\text { [Medicago truncatula] }\end{array}$ & $3.00 \mathrm{E}-046$ & 75.00 & XP_003617490.1 \\
\hline
\end{tabular}


Table 5 Selected Torvum transcripts annotated as $\mathbf{R}$ genes with an expression ratio in Torvum of at least 1.3 (infected vs control)

\begin{tabular}{|c|c|c|c|c|c|c|c|c|c|}
\hline ID & $\begin{array}{l}\text { B2GO sequence } \\
\text { description }\end{array}$ & Length & Best hit description & $\begin{array}{l}\text { Eggplant mean } \\
\text { expr control }\end{array}$ & $\begin{array}{l}\text { Eggplant mean } \\
\text { expr infected }\end{array}$ & $\begin{array}{l}\text { Torvum mean } \\
\text { expr control }\end{array}$ & $\begin{array}{l}\text { Torvum mean } \\
\text { expr infected }\end{array}$ & $\begin{array}{l}\text { Eggplant } \\
\text { expr ratio }\end{array}$ & $\begin{array}{l}\text { Torvum } \\
\text { expr ratio }\end{array}$ \\
\hline Tor5_c12566 & $\begin{array}{l}\text { Disease resistance } \\
\text { identical }\end{array}$ & 710 & $\begin{array}{l}\text { Gi|54261825|gb|AAV31175.1|Putative disease resistance } \\
\text { protein identical [Solanum tuberosum] }\end{array}$ & 168.426 & 396.871 & 485.109 & 654.998 & 2.356 & 1.350 \\
\hline Tor5_c14147 & $\begin{array}{l}\text { Leucine-rich repeat } \\
\text { containing }\end{array}$ & 493 & $\begin{array}{l}\text { Gi|212717155|gb|ACJ37419.1|NBS-LRR disease resistance } \\
\text { protein [Glycine max] }\end{array}$ & 1030.461 & 801.279 & 370.852 & 511.059 & 0.778 & 1.378 \\
\hline Tor5_c15732 & $\begin{array}{l}\text { Nbs-Irr resistance } \\
\text { protein }\end{array}$ & 498 & $\begin{array}{l}\text { Gi|224117364|ref|XP_002317554.1|nbs-Irr resistance protein } \\
\text { [Populus trichocarpa] > gi|222860619|gb|EEE98166.1| nbs-Irr } \\
\text { resistance protein [Populus trichocarpa] }\end{array}$ & 689.272 & 692.443 & 258.673 & 398.725 & 1.005 & 1.541 \\
\hline Tor5_c2525 & $\begin{array}{l}\text { Af202179_1disease } \\
\text { resistance protein bs2 }\end{array}$ & 664 & $\begin{array}{l}\text { Gi|6456755|gb|AAF09256.1|AF202179_1disease resistance } \\
\text { protein BS2 [Capsicum chacoense] }\end{array}$ & 171.605 & 69.228 & 1736.174 & 2279.920 & 0.403 & 1.313 \\
\hline Tor5_c4459 & $\begin{array}{l}\text { Nbs-Irr type resistance } \\
\text { protein }\end{array}$ & 510 & Gi|83630761|gb|ABC26878.1|NRC1 [Solanum lycopersicum] & 1792.413 & 1541.649 & 760.225 & 1283.284 & 0.860 & 1.688 \\
\hline Tor5_c4728 & \multirow{3}{*}{$\begin{array}{l}\text { Disease resistance } \\
\text { identical disease } \\
\text { resistance protein }\end{array}$} & \multirow[t]{2}{*}{625} & Gi|83630761|gb|ABC26878.1|NRC1 [Solanum lycopersicum] & \multirow[t]{2}{*}{196.591} & \multirow[t]{2}{*}{152.134} & \multirow[t]{2}{*}{449.926} & \multirow[t]{2}{*}{664.659} & \multirow[t]{2}{*}{0.774} & \multirow[t]{2}{*}{1.477} \\
\hline \multirow[t]{2}{*}{ Tor5_c6199 } & & & gi|255561552|ref|XP_002521786.1|Disease resistance & & & & & & \\
\hline & & 715 & $\begin{array}{l}\text { Protein RPP13 putative [Ricinus communis] > gi|223538999| } \\
\text { gb|EEF40596.1| Disease resistance protein RPP13. putative } \\
\text { [Ricinus communis] }\end{array}$ & 233.431 & 212.023 & 197.292 & 304.554 & 0.908 & 1.544 \\
\hline Tor5_c7069 & $\begin{array}{l}\text { Nbs-Irr resistance } \\
\text { protein }\end{array}$ & 685 & $\begin{array}{l}\text { Gi|15418712|gb|AAG31015.1|tospovirus resistance protein C } \\
\text { [Solanum lycopersicum] }\end{array}$ & 294.835 & 199.927 & 811.956 & 1100.840 & 0.678 & 1.356 \\
\hline Tor5_c7274 & $\begin{array}{l}\text { Disease resistance } \\
\text { protein }\end{array}$ & 608 & $\begin{array}{l}\text { Gi|323370547|gb|ADX43928.1|ADR1 [Solanum } \\
\text { tuberosum] }\end{array}$ & 11454.467 & 12324.265 & 1568.053 & 2488.333 & 1.076 & 1.587 \\
\hline Tor5_c8985 & $\begin{array}{l}\text { Disease resistance- } \\
\text { dirigent domain- } \\
\text { containing protein }\end{array}$ & 490 & $\begin{array}{l}\text { Gi|224112881|ref|XP_002316318.1|predicted protein } \\
\text { [Populus trichocarpa] > gi|222865358|gb|EEF02489.1| } \\
\text { predicted protein [Populus trichocarpa] }\end{array}$ & 1862.947 & 777.762 & 678.101 & 992.523 & 0.417 & 1.464 \\
\hline Tor5_c9198 & $\begin{array}{l}\text { Nbs-Irr resistance } \\
\text { protein }\end{array}$ & 672 & $\begin{array}{l}\text { Gi|3426261|gb|AAC32253.1/disease resistance gene } \\
\text { homolog Mi-copy1 [Solanum lycopersicum] }\end{array}$ & 360.807 & 155.364 & 188.721 & 282.809 & 0.431 & 1.499 \\
\hline Tor5_rep_c1655 & $\begin{array}{l}\text { Disease resistance } \\
\text { response protein }\end{array}$ & 803 & $\begin{array}{l}\text { Gi|224105209|ref|XP_002313728.1|predicted protein } \\
\text { [Populus trichocarpa] >gi|222850136|gb|EEE87683.1| } \\
\text { predicted protein [Populus trichocarpa] }\end{array}$ & 77.749 & 138.308 & 345.620 & 512.257 & 1.779 & 1.482 \\
\hline Tor5_rep_c4425 & $\begin{array}{l}\text { Nbs-Irr resistance } \\
\text { protein }\end{array}$ & 574 & $\begin{array}{l}\text { Gi|15418710|gb|AAG31014.1|tospovirus resistance protein B } \\
\text { [Solanum lycopersicum] }\end{array}$ & 224.075 & 149.135 & 339.977 & 456.547 & 0.666 & 1.343 \\
\hline Tor5_rep_c7021 & $\begin{array}{l}\text { Disease resistance } \\
\text { protein }\end{array}$ & 519 & $\begin{array}{l}\text { Gi|53749455|gb|AAU90310.1/hypothetical protein } \\
\text { STB1_54t00008 [Solanum tuberosum] }\end{array}$ & 252.559 & 282.853 & 229.561 & 303.609 & 1.120 & 1.323 \\
\hline Tor5_rep_c9578 & $\begin{array}{l}\text { Disease resistance } \\
\text { protein }\end{array}$ & 472 & $\begin{array}{l}\text { Gi|53749455|gb|AAU90310.1/hypothetical protein } \\
\text { STB1_54t00008 [Solanum tuberosum] }\end{array}$ & 470.054 & 344.881 & 274.840 & 413.509 & 0.734 & 1.505 \\
\hline Tor5_s25440 & $\begin{array}{l}\text { Disease resistance } \\
\text { protein }\end{array}$ & 473 & $\begin{array}{l}\text { Gi|224117364|ref|XP_002317554.1|nbs-Irr resistance protein } \\
\text { [Populus trichocarpa] >gi|222860619|gb|EEE98166.1| nbs-Irr } \\
\text { resistance protein [Populus trichocarpa] }\end{array}$ & 10260.362 & 8458.349 & 1366.653 & 3326.171 & 0.824 & 2.434 \\
\hline
\end{tabular}


sesquiterpenoid genes $[17,21]$. This fact may be attributable to the limited number of genes tested in previous transcriptional profiling studies, and/or to further factors as genotypes under investigation and sampling time. Transcriptional induction of sesquiterpenoid genes associated to the resistant genotype Torvum, but not to the susceptible counterpart eggplant, strongly points to sesquiterpenoids as key effectors of Torvum resistance against $M$. incognita and sheds lights on their activation mode and relative contribution to the battery of Torvum defense strategies.

Overall, it appears that Torvum biosynthetic resources are channeled towards sesquiterpene biosynthesis at the expense of distinct biosynthetic branches. Further work based on the Torvum sequences reported here will likely provide the tools for an in-depth understanding of Torvum responses ultimately pointing to key phytoalexin products.

\section{Identification of Torvum resistance gene analogs}

Several resistance genes against plant-parasitic nematodes have been cloned [12]. Among them the best-studied is the tomato gene $M i$, which exhibits a broad resistance pattern to root-knot nematodes as well as to phloem-feeding insects, including Macrosiphum euphorbiae (potato aphid) and to the white fly Bemisia tabaci. Further nematode $\mathrm{R}$ genes cloned are: Hs1pro-1, Hero, Gpa2, Gro1-4, Rhg1 and Rhg $4 R$ [12].

Several aspects of the interaction among Torvum and Meloydogine would be consistent with an early rejection mechanism as ensured by vertical resistance (i.e. mediated by Avirulence-Resistance cognate gene interaction). In the Additional file 10 we report the 81 Torvum transcripts with annotations referring to candidate $\mathrm{R}$ genes analogs (RGAs). Among these, 28 (34\%) and 47 (58\%) showed enhanced expression in infected $v s$. control samples, respectively, in eggplant and Torvum. While no transcriptional modulation is strictly required for a $\mathrm{R}$ gene to be considered a candidate $\mathrm{R}$ gene (transcription of many $\mathrm{R}$ genes is not responsive to pathogen infection) several active $\mathrm{R}$ genes show moderate level of pathogen responsiveness in terms of transcription (e.g. 30\% induction or more over controls), e.g. Xa1, Xa27 [49,50]. Thus, monitoring the expression patterns of Torvum candidate R genes analogs (RGAs) can help pointing to RGAs of interest [51]. Table 5 enlists 16 Torvum transcripts annotated as disease resistance genes showing an expression ratio (infected vs. control) of at least 1.3. Only one of these Torvum induced transcripts has a validated counterpart in eggplant (tor5_c4459, slightly downregulated as a consequence of infection) pointing to major sequence divergence and/or lack of counterparts in eggplants for this set of induced Torvum candidate resistance genes. Intriguingly, among the candidate induced RGAs one shows as best hit a homologous to Mi nematode resistance gene (tor5_c9198).

Figure 8 depicts a multiple alignment and associated dendrogram encompassing selected Torvum RGAs and the most $\mathrm{C}$-terminal 200 residues of known $\mathrm{R}$ genes (boxed in red). Protein alignment was made for Torvum RGAs by selecting the longest ORF. As expected, Torvum sequences by design align to the most Cterminal regions of $\mathrm{R}$ genes (where the highly variable LRR region is placed) and only the most $\mathrm{C}$-terminal 100-150 AA of alignments are shown. Despite the fact the aligned regions are the poorly conserved LRR (Leucine Rich Repeat) regions, several Torvum transcripts show homology and cluster close to distinct R-prototype resistance genes and appear good candidates for future assessment of their role as true $\mathrm{R}$ genes.

\section{qPCR validation of selected genes}

In order to validate our microarray expression results, we choose six sequences (Table 6) among both upregulated and downregulated DEG of particular relevance as discussed above. Overall, despite the correlation among qPCR and array data $(0,704)$ was non-significant according to Pearson's product-moment correlation $(\mathrm{p}=0,118, \mathrm{n}=6)$, the direction of change in expression of qPCR and microarray was in agreement for all the tested transcripts (6 of 6).

\section{Conclusions}

We conducted a cost-effective global transcriptome profiling in Solanum torvum, a non-model species, by combining NGS pyrosequencing and microarray technology. As a first step, we generated a 3' transcript catalogue for Torvum by assembling $500-600$ bp reads from a normalized library. By limiting the sequencing to the 3 ' region we improved average coverage while conserving specificity (as less conserved 3' UTR regions are covered). This catalogue represents a substantial advancement along characterization of Torvum transcriptome, since even at the relaxed stringency of an $10^{-6}$ Expect value more than $60 \%$ of Torvum unigenes in our catalogue do not have Blast hits in available Torvum databases. The catalogue was subsequently used to design a custom chip for profiling transcriptome changes as a consequence of nematode infection in nematode-resistant species Torvum and the related nematode-susceptible species eggplant. To assess expression results for the heterologous hybridization conducted with eggplant samples, we developed an in silico validation strategy which can be applied in general to extend the use of speciesspecific chips to samples from phylogenetically related species devoid of a chip. This allows to define, for such heterologous hybridizations, pool of genes whose hybridization data are expected to be more reliable. Finally, the 
a

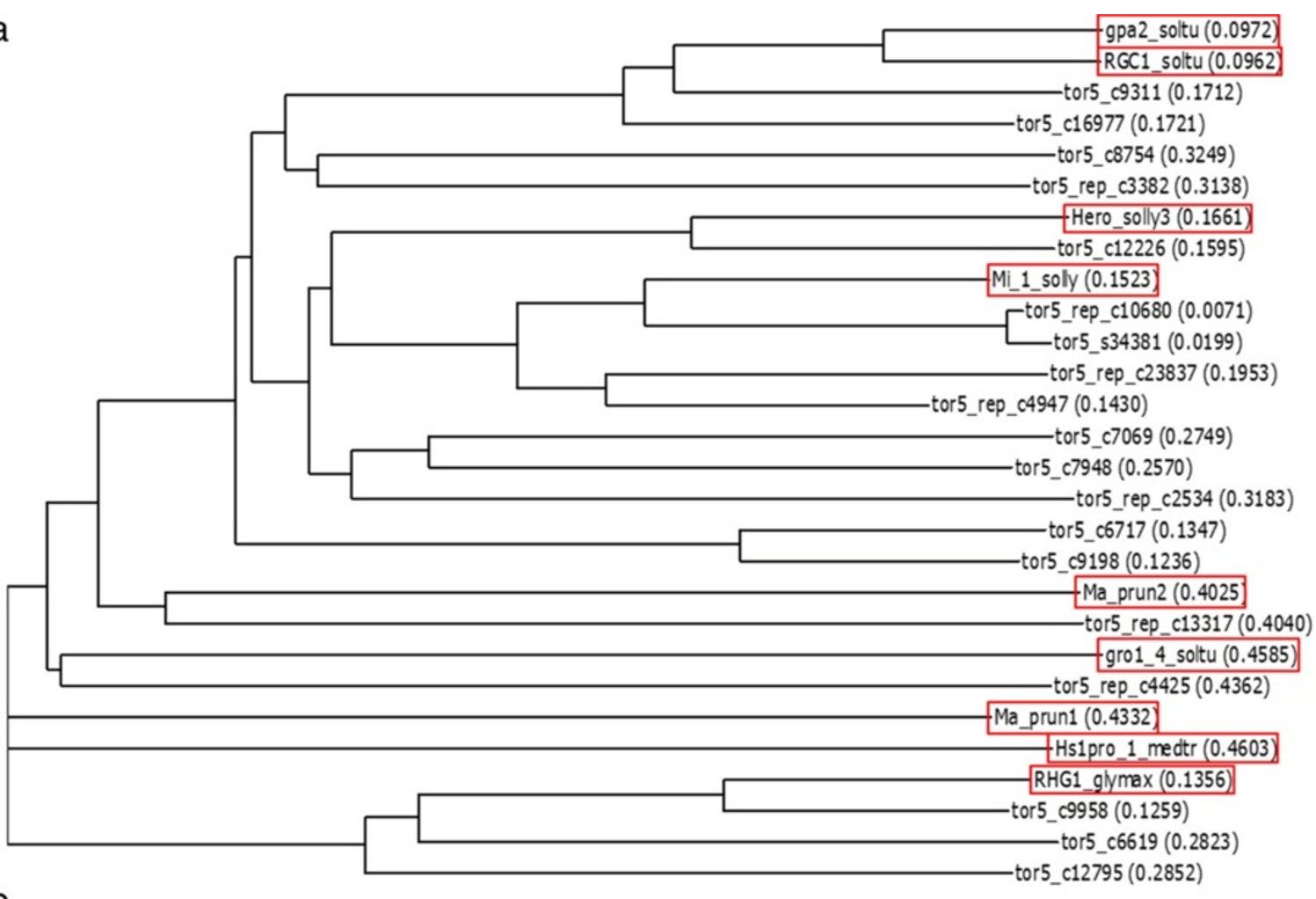

b

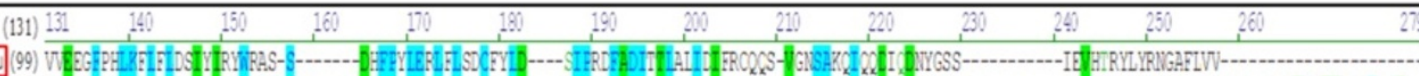

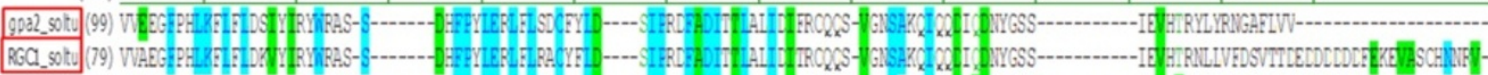
tor_c16977 (1) - -.--

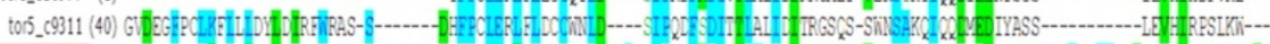

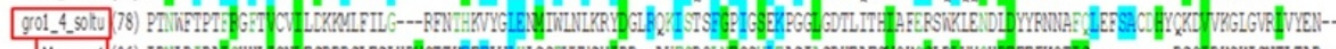

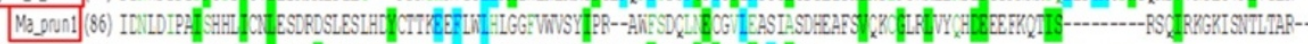

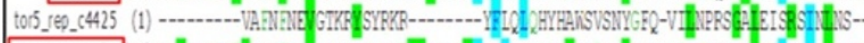

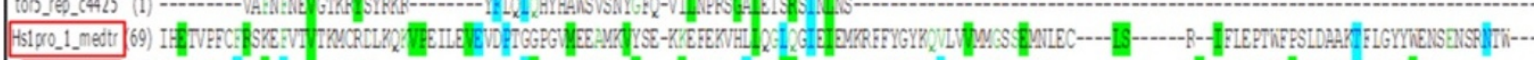

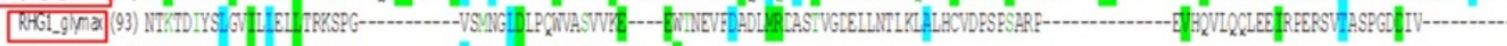

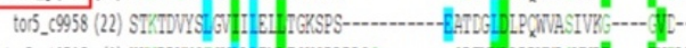

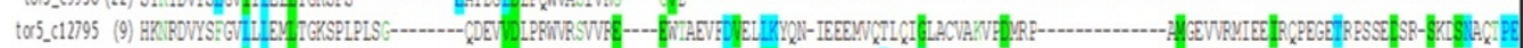

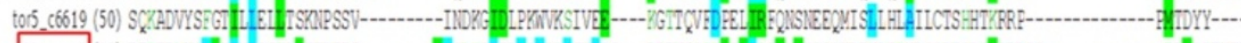

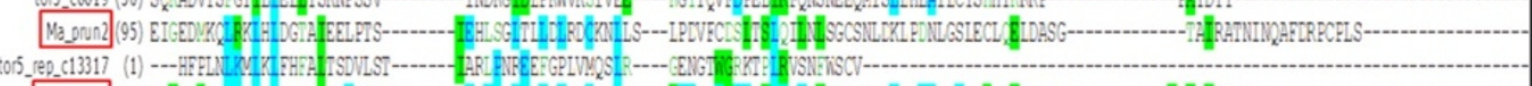

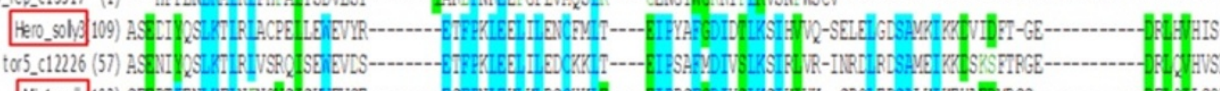

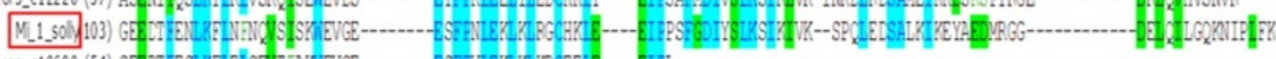

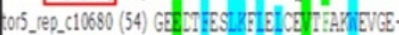

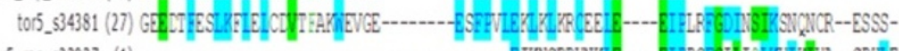

.

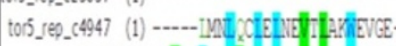

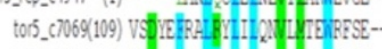

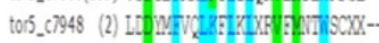

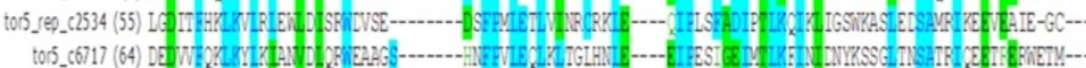

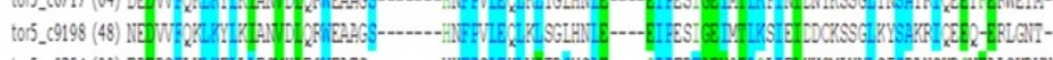

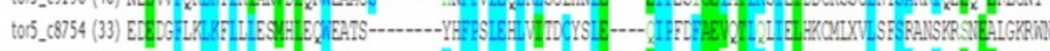

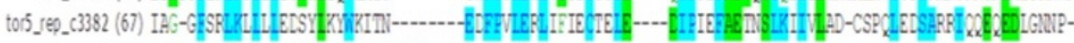

Consensos(131) E E IR I I VI W STFY IE FE IE L L C IE B EIF FGDI TIR I I

L SA I CED

TSISSAEST

Affucronitinged-

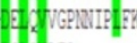

Ad

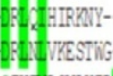

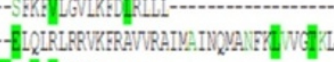

RIPd]fing

Figure 8 (See legend on next page.) 
(See figure on previous page.)

Figure 8 Multiple alignment of selected Torvum translated transcripts to known nematode resistance gene proteins. The longest ORF of Torvum transcripts were aligned to the most C-terminal residues of a selection of well characterized (boxed in red) plant nematode $\mathrm{R}$ genes. a) dendrogram. b) sequence alignment detail. Plant nematode R genes: Gpa2_soltu=disease resistance protein Gpa2 Solanum tuberosum (AAF04603.1); RGC1_soltu= RGC1 Solanum tuberosum (AAF76163.1); Hero_solly3=Hero resistance protein 3 homologue Solanum lycopersicum (CAD29727.1); Mi_1_solly=plant resistance protein Solanum lycopersicum (NP_001234622.1); Ma_prun2=, nematode resistance-like protein Prunus cerasifera (CAR94516.1); Gro1_4_solu=nematode resistance protein Solanum tuberosum (AAP44390.1); Ma_prun1=nematode resistance-like protein Prunus cerasifera (CAR94516.1); Hs1 pro_1_medtr=nematode resistance HS1 pro1 protein Medicago truncatula (AES99551.1); RHG1_glymax=, receptor-like kinase RHG1 Glycine max (NP_001235765.1).

expression profiling of Torvum responses to nematode infection reveals a focused upregulation of various classes of chitinases and, for the first time, of sesquiterpenoids biosynthetic genes and. On the other hand, no such responses are detectable in eggplant, where a large but sparse and incoherent gene modulation occurs, probably as a consequence of successful establishment of infection. The availability of the long sequence tags in Torvum catalogue will allow precise identification of active nematocide/ nematostatic compounds and associated enzymes posing the basis for the exploitation of these resistance mechanisms in other species.

\section{Methods}

Plant materials and growth conditions

Seeds of Solanum torvum Sw accession TG1 [1] and eggplant (Solanum melongena L.) breeding line 1F5(9) were sown in a seed-plot for germination. Seedlings about $10 \mathrm{~cm}$ tall at the second-leaf stage were singly transplanted into $10 \mathrm{~cm}$ diameter plastic pots, each containing $500 \mathrm{cc}$ of mixture sterilized sandy soil: $70 \%$ sand $+15 \%$ leca + $10 \%$ clay (sterilized at $70^{\circ} \mathrm{C}$ for 24 hours) $+5 \%$ organic matter. The pots were maintained in controlled chambers at $24 \pm 2^{\circ} \mathrm{C}, 60 \%$ relative humidity, with a 16 -h light $/ 8$-h dark regimen. Plants were watered with tap water at necessity and fertilized every two weeks with a 20-20-20 NPK fertilizer.

\section{Nematode culture and inoculation}

Root-knot nematode (RKN), Meloidogyne incognita, was maintained in the greenhouse on tobacco (Nicotiana tabacum L.) plants [52], egg masses were extracted with
$0.5 \%(\mathrm{v} / \mathrm{v}) \mathrm{NaOCl}$ and second stage larvae (J2) hatched as described by [53]. Plants were inoculated with about 250-300 J2 and eggs pouring into three holes in the soil just around the base of the plant stem. Pots were maintained at same conditions, as previously indicated, and checked periodically. Treatments and controls were replicated five times. Inoculated roots were observed for galling and egg-masses development two months later inoculation. For transcriptome study, Torvum control and infected plants at 14 days post inoculation (dpi) were produced. Root tissues collected from each type of plant were then used for RNA extractions and microarray analysis.

\section{Nematode staining and infection assessment}

Roots were removed from soil and washed in water for few minutes. Then, each root system was dipped in a $0,15 \mathrm{~g} / \mathrm{l}$ phloxine $\mathrm{B}$ solution for 15 minutes to point out galls and egg masses. Stained roots were observed under the microscope to assess nematode infectivity by estimating the root-galling index [54] and egg masses [55] on a 05 scale: root-gall index (0: no gall; 1 : $1-5$ small galls; $2:<25 \%$ roots with galls; $3: 25-50 \% ; 4: 50-75 \% ; 5:>75 \%$ roots with galls); egg mass or egg-laying females (0: no egg mass; 1: 1-2 egg masses; 2: 3-10 egg masses; 3: 11-30 egg masses; 4: 31-100 egg masses; 5: >100 egg masses). Nematode infectivity tests were also conducted by employing highly susceptible plants such as $S$. melongena.

\section{RNA extraction}

RNA samples were extracted, as total RNA, from mockinoculated and infected Torvum and eggplant roots

Table 6 qPCR validation of microarray results

\begin{tabular}{|c|c|c|c|c|c|c|}
\hline ID & Function & $\begin{array}{c}\text { Fold change } \\
\text { qPCR }\end{array}$ & $\begin{array}{l}\text { Exp. trend } \\
\text { qPCR }\end{array}$ & $\begin{array}{c}\text { Fold change } \\
\text { chip }\end{array}$ & $\begin{array}{l}\text { Exp. trend } \\
\text { chip }\end{array}$ & $\begin{array}{l}\text { Consistency among } \\
\text { qPCR and chip }\end{array}$ \\
\hline Tor5_c3883 & Wound-ind. Prot win1 & 1.88 & + & 3.86 & + & YES \\
\hline Tor5_rep_c1712 & Acidic endochitinase & 1.24 & + & 2.12 & + & YES \\
\hline Tor5_c8583 & Class2 chitinase & 5.22 & + & 3.44 & + & YES \\
\hline Tor5_c6621 & Class $\vee$ chitinase & 3.37 & + & 2.56 & + & YES \\
\hline Tor5_rep_c483 & Ent-kaurene ox & 0.66 & - & 0.49 & - & YES \\
\hline Tor5_c3988 & Ggdp synth. & 0.51 & - & 0.39 & - & YES \\
\hline
\end{tabular}


(three biological replicates for each condition) by means of the Nucleospin RNA plant Kit (MACHEREY-NAGEL GmbH \& Co., Düren, Germany) at 0 and 14 dpi. Total RNA quality was assessed using a Bioanalyzer 2100 Expert (B.02.07.SI532-, Agilent Technologies, Inc). In all the samples tested, RIN (RNA Integrity number) resulted to be above 9, while the concentration ranged among 100 and $120 \mathrm{ng} / \mu \mathrm{l}$.

\section{qRT-PCR experiments}

Real time PCR analysis were carried out in a Applied Biosystems 7500HT Fast Real Time PCR System. The $20 \mu \mathrm{l}$ reaction mixture consisted of $10 \mu \mathrm{l}$ BIORAD iTaq ${ }^{\text {TM }}$ universal SYBR ${ }^{\circledR}$ Green supermix, $2 \mu$ l of sample cDNA, $200 \mathrm{nM}$ forward and reverse primers and nuclease-free water. The reference genes used were Glutatione peroxidase and Diaminopimelate carboxilase; they were chosen among a list of the best performing housekeeping genes, since their expression was uniform in all samples preliminarily tested. Prior to perform correlation analyses, the data were tested for normality using the Shapiro-Francia test. The data were normally distributed and Pearson's correlation was used.

\section{Custom chip design}

Total RNA was extracted from Torvum tissues (roots and young leaves) grown in a wide range of conditions to allow for ample gene transcription. Such treatments included low temperatures $\left(4^{\circ} \mathrm{C} ; 30\right.$ minutes $)$, high temperatures (over $30{ }^{\circ} \mathrm{C}$ with peaks of $40^{\circ} \mathrm{C}$ as reached in a non-cooled glasshouse during the whole day for a 4 days), soil-borne fungus (Verticillium dahliae) and nematodes (Meloidogyne incognita) with sampling at 1, 7 and $14 \mathrm{dpi}$, wounding (punching holes with a needle, harvest after 1 and 7 days) and drought stress (harvest after 14 days without water supply) RNA samples were pooled and, from 500 ng of total RNA a -3' cDNA library (500$600 \mathrm{bp}$ ) was generated (Eurofins MWG operon) with oligo(dT) primer (first-strand) and random priming (second-strand) and subsequently normalized.

De novo assembly of Torvum reads was undertaken with MIRA 3.0.5 [22] in de novo assembly mode and conducted with 454-specific parameters.

RNA labelling and hybridizations of the Custom 90K CombiMatrix array were as detailed in Bellin et al., [5]. Gene-specific oligonucleotides were designed with OligoArray 2.1 software [25]. Oligoarray parameters were tuned to for the observed GC content of $38.23 \%$ for the unigenes (e.g. Tm 79-86; GC content range 34-60). The final number of probes in the chip was reduced to 30,000 , by excluding less specific probes (probes hybridizing with more than one target), in order to allow a triplicate probe layout in the 90k-features Combimatrix gene chip. The final layout consisted in 24,394 probes representative of contigs and 5,606 probes derived from singletons.

\section{Miscellaneous bioinformatic techniques}

For Blast2GO annotation of Torvum catalogue, the 23,284 unigenes included in the chip layout for which an hybridization signal could be obtained were blasted (BlastX) against NCBI non-redundant database. Expect value was set to $1.0 \mathrm{E}^{-6}$, HSP length cutoff was 100 and up to 20 hits were allowed to be retrieved. Annotation was according to default parameters with GO weight set to 5 with an annotation cutoff of 30 and minimum HSP of 10. Call of differentially expressed genes (DEG) was performed with $\mathrm{R}$ package LIMMA (Linear Models Microarray Analysis) [56] and custom functions. Genes were considered differentially expressed if exhibiting at least a 2-fold change and a False Discovery Rate (FDR) $<=0.1$. For chip extension technique eggplant entries from NCBI EST division (98,089 entries as July 2012), and eggplant tentative consensus from various expression databases including DFCI eggplant gene index [57] PlantGDB PUT [58] and SolEST [59] were combined and queried with chip probe sequences using local BlastN at a relaxed stringency (Expect value 10). The Blast output was subsequently parsed by custom scripts to filter probes based on alignment parameters expected to influence hybridization strength. Heatmaps was generated with custom scripts based on heatmap. 2 function as available in the 'gplots' Bioconductor package. Multiple alignments were generated with AlignX module of Vector NTI. Unless otherwise stated, other graphical outputs were generated with custom $\mathrm{R}$ (version 2.15 ) and Python scripts.

\section{Availability of data}

Accessions for dataset are the following: Sequence Read Archive (SRA; http://www.ncbi.nlm.nih.gov/Traces/sra/): SRA experiment: SRX268284; SRA run: SRR830592; Transcriptome shotgun assembly (TSA; http://www.ncbi. nlm.nih.gov/genbank/tsa): GAIC00000000; gene expression omnibus (GEO; http://www.ncbi.nlm.nih.gov/geo/): data have been submitted and are under NCBI processing.

\section{Additional files}

Additional file 1: De novo assembly parameters. (a) Distribution of contig length in raw assembly output and final chip layout. (b) The distribution of average contig coverage (rounded to an integer value) in raw assembly output. Contigs are grouped based on bins as detailed on $\mathrm{x}$ axis. Singletons are displayed as contigs with read coverage equal to one.

Additional file 2: Specificity of Torvum probes designed for custom chip. The specificity or probes designed by oligoarray over the raw set of Torvum unigenes is shown. Probes strictly specific for only one Torvum unigene have only one associated target.

Additional file 3: Pearson correlation coefficients.

Additional file 4: Torvum DEG. 
Additional file 5: Torvum unigene annotations.

Additional file 6: Torvum unigene sequences.

Additional file 7: Enriched GO terms.

Additional file 8: Overall eggplant expression values as influenced by homology among Torvum probes and eggplant transcripts. Effect on mean expression values (left side of $Y$ axis ) and number of retained probes (right side of $Y$ axis, reddish bars) as influenced by percent alignment ( $X$ axis) and number of mismatches $(0,1$ or 2 labels in lines). Panel (a) to (e): the effect of imposing an oligo alignment start (from 5 side) of none, 20, 10, 5 and 1, respectively, is shown. Panel (f): effect of different number of randomly chosen probes on expression values.

\section{Additional file 9: Eggplant DEGs.}

Additional file 10: Torvum RGAs.

\section{Abbreviations}

Torvum: Solanum Torvum; RGAs: Resistance gene analogs.

\section{Competing interests}

The authors declare that they have no competing interests.

\section{Authors' contributions}

PB carried bioinformatic procedures and drafted the manuscript. TS prepared RNA samples. TI and CS grew Torvum and eggplant plants and conducted nematode inoculations and scored results. AL participated in annotation analysis. MB conducted Real-Time validations. GLR, LC and SS participated in studying, design and analysis and participated in drafting the manuscript. ES conceived the study, analyzed Real-Time validation data and participated in drafting the manuscript. All authors read and approved the final manuscript.

\section{Acknowledgements}

The authors of this paper were supported by "NEMAMEL" project, funded by Consiglio per la Ricerca e la Sperimentazione in Agricoltura.

\section{Author details}

${ }^{1}$ Consiglio per la Ricerca e la Sperimentazione in Agricoltura, Genomics Research Centre, via S Protaso 302, I-29107, Fiorenzuola d'Arda (PC), Italy. ${ }^{2}$ Consiglio per la Ricerca e la Sperimentazione in Agricoltura, Unità di Ricerca per l'Orticoltura, Montanaso Lombardo (LO), Italy. ${ }^{3}$ Consiglio per la Ricerca e la Sperimentazione in Agricoltura, Centro di ricerca per l'agrobiologia e la pedologia, Cascine del Riccio, 50125, Firenze, Italy. ${ }^{4}$ UNIMORE, Scienze Agrarie e degli Alimenti, Università degli Studi di Modena e Reggio Emilia, via Giovanni Amendola 2, Padiglione Besta, Reggio Emilia 42122, Italy. ${ }^{5}$ Consiglio per la Ricerca e la Sperimentazione in Agricoltura, Unità di Ricerca per l'Orticoltura, Monsampolo del Tronto, AP, Italy.

Received: 22 February 2013 Accepted: 5 August 2013

Published: 9 August 2013

\section{References}

1. Gousset C, Collonnier C, Mulya K, Mariska I, Rotino GL, Besse P, Servaes A Sihachakr D: Solanum torvum, as a useful source of resistance against bacterial and fungal diseases for improvement of eggplant (S. melongena L.). Plant Sci 2005, 168:319-327.

2. Aribaud $M$, Jégo $S$, Wicker $E$, Fock $I$ : Ralstonia solanacearum induces soluble amine-oxidase activity in Solanum torvum stem calli. Plant Physiol Biochem 2010, 48:787-96.

3. Yamaguchi H, Fukuoka H, Arao T, Ohyama A, Nunome T, Miyatake $\mathrm{K}$ Negoro S: Gene expression analysis in cadmium-stressed roots of a low cadmium-accumulating solanaceous plant. Solanum torvum. J Exp Bot 2010, 61(2):423-437.

4. Malone $\mathrm{JH}$, Oliver $\mathrm{B}$ : Microarrays, deep sequencing and the true measure of the transcriptome. BMC Biol 2011, 9:34.

5. Bellin D, Ferrarini A, Chimento A, Kaiser O, Levenkova N, Bouffard P, Delledonne M: Combining next-generation pyrosequencing with microarray for large scale expression analysis in non-model species. BMC Genomics 2009, 10:555.

6. Zenoni S, D'Agostino N, Tornielli GB, Quattrocchio F, Chiusano ML, Koes R, Zethof J, Guzzo F, Delledonne M, Frusciante L, et al: Revealing impaired pathways in the an11 mutant by high-throughput characterization of
Petunia axillaris and Petunia inflata transcriptomes. Plant J 2011, 68(1):11-27.

7. Webster JM: Introduction. In Principles and practice of nematode control in crops. Edited by Brown RH: Kerry BR Academic Press, Melbourne; 1987:1-12.

8. Nicol JM, Turner SJ, Coyne DL, Den-Nijs L, Hockland S, Tahna Maafi Z: Current nematode threats to world agriculture. In Genomics and Molecular Genetics of Plant-Nematode Interactions. Edited by Jones J et al. Springer Science+Business Media BV; 2011. DOI 10.1007/978-94007-0434-3_2

9. The American Phytopathological Society. http://www.apsnet.org/edcenter/ intropp/lessons/Nematodes/Pages/RootknotNematode.aspx

10. Bellafiore S, Shen Z, Rosso M-N, Abad P, Shih P, Briggs SP: Direct identification of the Meloidogyne incognita secretome reveals proteins with host cell reprogramming potential. PLoS Pathog 2008, 4(10):e1000192.

11. Cai D, Kleine M, Kifle S, Harloff HJ, Sandal NN, Marcker KA, Klein-Lankhorst RM, Salentijn EM, Lange W, Stiekema WJ, Wyss U, Grundler FM, Jung C: Positional cloning of a gene for nematode resistance in sugar beet. Science 1997, 275:832-834.

12. Williamson VM, Kumar A: Nematode resistance in plants: the battle underground. Trends Genet 2006, 22:396-403.

13. Milligan SB, Bodeau J, Yaghoobi J, Kaloshian I, Zabel P, Williamson VM: The root knot nematode resistance gene $M i$ from tomato is a member of the leucine zipper, nucleotide binding, leucine-rich repeat family of plant genes. The Plant cell 1998, 10:1307-19.

14. Claverie M, Dirlewanger E, Bosselut N, Van-Ghelder C, Voisin R, Kleinhentz M, Lafargue B, Abad P, Rosso MN, Chalhoub B, et al: The Ma gene for complete spectrum resistance to Meloidogyne species in prunus is a TNL with a huge repeated C-terminal post-LRR region. Plant Physiol 2011, 156(2):779-792.

15. Wang C, Ulloa M, Mullens TR, Yu JZ, Roberts PA: QTL analysis for transgressive resistance to Root-Knot Nematode in interspecific cotton (Gossypium spp.) progeny derived from susceptible parents. PLOS ONE 2012, 7(4):e34874. doi:10.1371/journal.pone.0034874

16. Wang C, Ulloa M, Roberts PA: Identification and mapping of microsatellite markers linked to a root-knot nematode resistance gene (rkn1) in Acala NemX cotton (Gossypium hirsutum L.). Theor Appl Genet 2006, 112:770-777.

17. Hammes UZ, Schachtman DP, Berg RH, Nielsen E, Koch W, Mclntyre LM, Taylor CG: Nematode-induced changes of transporter gene expression in Arabidopsis roots. Mol Plant Microbe Interact 2005, 18:1247-57.

18. Schaff JE, Nielsen DM, Smith CP, Scholl EH, Bird DM: Comprehensive transcriptome profiling in tomato reveals a role for glycosyltransferase in Mi-mediated nematode resistance. Plant physiology 2007, 144:1079-92.

19. Jammes F, Lecomte $P$, de-Almeida-Engler J, Bitton F, Martin-Magniette M-L, Renou JP, Abad P, Favery B: Genome-wide expression profiling of the host response to root-knot nematode infection in Arabidopsis. The Plant journal 2005, 44:447-58.

20. de-Deus Barbosa AEA, da-Rocha FR, de Lima e Souza DDS, Freire É, de Oliveira Neto OB, Viana AAB, Togawa RC, Guimarães LM, Martins NF, Cia E, Fernandez D, de Lima LM, Silva MCM, Rocha TL, Grossi-de-Sa MF: Differentially expressed genes in cotton plant genotypes infected with Meloidogyne incognita. Plant Sci 2009, 177:492-497.

21. Ibrahim HMM, Hosseini P, Alkharouf NW, Hussein EHA, Gamal El-Din AEKY, Aly MAM, Matthews BF: Analysis of gene expression in soybean (Glycine max) roots in response to the root knot nematode Meloidogyne incognita using microarrays and KEGG pathways. BMC genomics 2011, $12: 220$

22. Chevreux B, Pfisterer $T$, Drescher B, Driesel AJ, Muller WE, Wetter T, Suhai $S$ : Using the miraEST assembler for reliable and automated mRNA transcript assembly and SNP detection in sequenced ESTs. Genome Res 2004, 14(6):1147-1159.

23. Rensink WA, Lee Y, Liu J, lobst S, Ouyang S, Buell CR: Comparative analyses of six solanaceous transcriptomes reveal a high degree of sequence conservation and species-specific transcripts. BMC Genomics 2005, 6:124.

24. Olmstead RG, Bohs L, Migid HA, Santiago-Valentin E, Garcia FV, Collier SM: A molecular phylogeny of the Solanaceae. Taxon 2008, 57(4):1159-1181.

25. Rouillard JM, Zuker M, Gulari E: OligoArray 2.0: design of oligonucleotide probes for DNA microarrays using a thermodynamic approach. Nucleic Acids Res 2003, 31(12):3057-3062.

26. Conesa A, Gotz S, Garcia-Gomez JM, Terol J, Talon M, Robles M: Blast2GO: a universal tool for annotation, visualization and analysis in functional genomics research. Bioinformatics 2005, 21(18):3674-3676. 
27. Bagnaresi P, Moschella A, Beretta O, Vitulli F, Ranalli P, Perata P: Heterologous microarray experiments allow the identification of the early events associated with potato tuber cold sweetening. BMC Genomics 2008, 9:176.

28. Das S, Ehlers JD, Close TJ, Roberts PA: Transcriptional profiling of root-knot nematode induced feeding sites in cowpea (Vigna unguiculata L. Walp.) using a soybean genome array. BMC Genomics 2010, 11:480.

29. Polesani M, Bortesi L, Ferrarini A, Zamboni A, Fasoli M, Zadra C, Lovato A Pezzotti M, Delledonne M, Polverari A: General and species-specific transcriptional responses to downy mildew infection in a susceptible (Vitis vinifera) and a resistant (V. riparia) grapevine species. BMC Genomics 2010, 11:117.

30. Mica E, Piccolo V, Delledonne M, Ferrarini A, Pezzotti M, Casati C, Del-Fabbro C, Valle G, Policriti A, Morgante M, Pesole G, Pè ME, Horner DS: High throughput approaches reveal splicing of primary microRNA transcripts and tissue specific expression of mature microRNAs in Vitis vinifera. BMC Genomics 2009, 10:558.

31. Zinov'eva SV, Udalova ZV, Vasil'eva IS, Vanyushkin SA, Paseshnichenko VA Role of isoprenoids in plant adaptation to biogenic stress induced by parasitic nematodes. Appl Biochem Microbiol 2001, 37(5):456-462.

32. Caillaud M-C, Dubreuil G, Quentin M, Perfus-Barbeoch L, Lecornte P, Engler JA, Abad P, Rosso M-N, Favery B: Root-knot nematodes manipulate plant cell functions during a compatible interaction. J Plant Physiol 2008, 165(1):104-113.

33. Zinov'eva SV, Vasyukova NI, Ozeretskovskaya OL: Biochemical aspects of plant interactions with phytoparasitic nematodes. App/ Biochem Microbiol 2004, 40(2):111-119.

34. Gortari MC, Hours RA: Fungal chitinases and their biological role in the antagonism onto nematode eggs. Mycol Prog 2008, 7(4):221-238.

35. Qiu J, Hallmann J, Kokalis-Burelle N, Weaver DB, Rodríguez-Kábana R, Tuzun S: Activity and differential induction of chitinase isozymes in soybean cultivars resistant or susceptible to root-knot nematodes. J Nematol 1997, 29(4):523.

36. Ornatowski W, Jayaraj J, Todd TC, Schapaugh WT, Muthukrishnan S, Trick HN: Introduction and constitutive expression of a tobacco hornworm (Manduca sexta) chitinase gene in soybean. In Vitro Cell Dev Biol Plant 2004, 40(3):260-265

37. Brants A, Brown CR, Earle ED: Trichoderma harzianum endochitinase does not provide resistance to Meloidogyne hapla in transgenic tobacco. J Nematol 2000, 32(3):289-296.

38. Wei B-Q, Xue Q-Y, Wei L-H, Niu D-D, Liu H-X, Chen L-F, Guo J-H: A novel screening strategy to identify biocontrol fungi using protease production or chitinase activity against Meloidogyne root-knot nematodes. Biocontrol Sci Technol 2009, 19(8):859-870.

39. Chan YL, Cai D, Taylor PWJ, Chan MT, Yeh KW: Adverse effect of the chitinolytic enzyme PjCHI-1 in transgenic tomato on egg mass production and embryonic development of Meloidogyne incognita. Plant Pathol 2010, 59(5):922-930.

40. Chen CC, Kumar HGA, Kumar S, Tzean SS, Yeh KW: Molecular cloning, characterization, and expression of a chitinase from the entomopathogenic fungus Paecilomyces javanicus. Curr Microbiol 2007, 55(1):8-13.

41. Kirby J, Keasling JD: Biosynthesis of plant isoprenoids: perspectives for microbial engineering. Annu Rev Plant Biol 2009, 60:335-55.

42. Takahashi S, Yeo Y-S, Zhao Y, O'Maille PE, Greenhagen BT, Noel JP, Coates RM, Chappell J: Functional characterization of premnaspirodiene oxygenase, a cytochrome P450 catalyzing regio- and stereo-specific hydroxylations of diverse sesquiterpene substrates. J Biol Chem 2007, 282(43):31744-54.

43. Daraselia ND, Tarchevskaya S, Narita JO: The promoter for tomato 3hydroxy-3 methylglutaryl coenzyme A reductase gene 2 has unusual regulatory elements that direct high-level expression. Plant Physiol 1996 112:727-33.

44. Chitwood DJ: Phytochemical based strategies for nematode control. Annu Rev Phytopathol 2002, 40:221-49.

45. Veech JA, McClure MA: Terpenoid aldehydes in cotton roots susceptible and resistant to the root-knot nematode, Meloidogyne incognita. J Nematol 1977, 9:225-9.

46. Khoshkhoo N, Hedin P, McCarty JC: Terpenoid aldehydes in root-knot nematode susceptible and resistant cotton plants. J Agric Food Chem 1994, 42:204-208.

47. Desjardins AE, McCormick SP, Plaisted RL, Brodie BB: Association between solavetivone production and resistance to Globodera rostochiensis in potato. J Agric Food Chem 1997, 45:2322-2326.
48. Alphey TJW, Robertson WM, Lyon GD: Rishitin a natural plant product with nematicidal activity. Revue de Nematologie 1988, 11:399-404.

49. Li Y, Xia Q, Kou H, Wang D, Lin X, et al: Induced Pib expression and resistance to Magnaporthe grisea are compromised by cytosine demethylation at critical promoter regions in rice. J Integr Plant Biol 2011, 53:814-823.

50. Ballini E, Morel J-B, Droc G, Price A, Courtois B, et al: A genome-wide metaanalysis of rice blast resistance genes and quantitative trait loci provides new insights into partial and complete resistance. Mol Plant Microbe Interact 2008, 21:859-868.

51. Bagnaresi $P$, Biselli C, Orrù L, Urso S, Crispino L, Abbruscato P, Piffanelli $P$, Lupotto $E$, Cattivelli L, Valè G: Comparative transcriptome profiling of the early response to magnaporthe oryzae in durable resistant vs susceptible rice (Oryza sativa L.) genotypes. PLOS ONE 2012, 7:e51609.

52. Irdani T, Caroppo S, Ambrogioni L: Response of Nicotiana tabacum plants overexpressing a glucocorticoid receptor to Meloidogyne incognita (Nematoda Tylenchida) infestation. Redia 2003, LXXXVI:35-38.

53. Hussey RS, Barker KR: A comparison of methods of collecting inocula of Meloidogyne spp. including a new technique. Plant Dis Rep 1973 57:1025-1028

54. Di-Vito M, Lamberti F, Carella A: La resistenza del pomodoro nei confronti dei nematodi galligeni: prospettive e possibilitá. Riv Agron 1979, 13:313-22.

55. Taylor CE, Sasser JN: Biology identification and control of root-knot nematodes (Meloidogyne species). Raleigh: Coop Publ Dep Plant Pathol, NC State Univ/ US Agency Int Aid; 1978

56. Smyth GK: L: Linear models for microarray data. In Bioinformatics and Computational Biology Solutions Using R and Bioconductor. Edited by Gentleman R, Carey V, Dudoit S, Irizarry R, Huber W. New York: Springer; 2005:397-420. Part V.

57. DFCl eggplant gene index. http://compbio.dfci.harvard.edu/.

58. PlantGDB. http://www.plantgdb.org

59. D'Agostino N, Traini A, Frusciante L, Chiusano ML: SolEST database: a "one-stop shop" approach to the study of Solanaceae transcriptomes. BMC Plant Biol 2009, 9:142

doi:10.1186/1471-2164-14-540

Cite this article as: Bagnaresi et al:: Solanum torvum responses to the root-knot nematode Meloidogyne incognita. BMC Genomics 2013 14:540.

\section{Submit your next manuscript to BioMed Central and take full advantage of:}

- Convenient online submission

- Thorough peer review

- No space constraints or color figure charges

- Immediate publication on acceptance

- Inclusion in PubMed, CAS, Scopus and Google Scholar

- Research which is freely available for redistribution
C BioMed Central 